\title{
LA CONSTITUCIÓN CUBANA DE 2019: \\ UN ANÁLISIS CRÍTICO
}

ALBERT NOGUERA FERNÁNDEZ 
SUMARIO

I. INTRODUCCIÓN. II. TRANSFORMACIONES SOCIO-ECONÓMICAS Y PROCESO CONSTITUYENTE MATERIAL EN CUBA (1991-2018): II.I. El Período Especial y la Ley de Reforma Constitucional de 12 de julio de 1992: II.I.1. Cambios en las formas de propiedad. II.I.2. La regulación del comercio exterior y la despenalización de la divisa. II.II. Retiro de Fidel Castro y transformaciones de la última década (2006-2017): II.II.1. Transformaciones en la propiedad agraria y la reforma de la Ley de vivienda. II.II.2. Las reformas en el trabajo y la seguridad social. II.II.3. La Ley de inversión extranjera de 2014. III. LA NUEVA CONSTITUCIÓN DE 2019: AVANCES Y DEFICIENCIAS: III.I. El procedimiento de aprobación de la Constitución. III.II. La inexistencia de supremacia y aplicabilidad directa de la Constitución. III.III. La carta de derechos: luces y sombras. III.IV. El Partido, la organización política y la participación ciudadana. III.V. La Administración territorial: eliminación de las APPP y creación del gobernador provincial. III.VI. La propiedad y el modelo económico. IV. CONCLUSIONES. 


\title{
LA CONSTITUCIÓN CUBANA DE 2019: UN ANÁLISIS CRÍTICO ${ }^{1}$
}

\author{
ALBERT NOGUERA FERNÁNDEZ²
}

\section{INTRODUCCIÓN}

La aprobación de la Constitución cubana de 1976 se ubicó claramente dentro de la influencia teórica y práctica del constitucionalismo creado por el mal llamado «socialismo real» de Europa oriental, sobre todo del soviético. Sin embargo, el contexto general que está detrás de este texto constitucional hace ya casi tres décadas que se desmoronó.

Hacía años que existía, entre los académicos cubanos en el interior de la isla, un debate y propuestas sobre la necesidad de redefinir el modelo constitucional del 76 que, a pesar de haber sufrido tres reformas en $1978^{3}, 1992^{4}$ y $2002^{5}$, estuvo vigente hasta hace pocos meses. Finalmente, en febrero de 2019 se aprobó, mediante referéndum, la nueva Constitución cubana de 2019. Ésta se compone del preámbulo y de 229 artículos (92 más que la actual Constitución).

El presente trabajo analizará el proceso que ha llevado a la actual reforma total de la Constitución en Cuba, así como el contenido del nuevo texto constitucional, comparándolo con aquel conjunto de constituciones aprobadas durante las últimas dos décadas en aquellos países latinoamericanos alineados ideológicamente con Cuba (principalmente, Venezuela, Bolivia y Ecuador), agrupadas bajo el llamado nuevo constitucionalismo latinoamericano.

${ }^{1}$ El presente artículo se ha elaborado en el marco del Proyecto de I+D: «La Constitución climática global: gobernanza y Derecho en un contexto complejo» financiado por el Ministerio de Economía y Competitividad para el trienio 2017-2019 (proyecto DER2016-80011-P).

2 Departamento de Derecho Constitucional, Ciencia Política y de la Administración. Facultad de Derecho. Universidad de Valencia. Edificio Departamental Occidental. Campus dels Tarongers. Avda. dels Tarongers, s/n. 46022 Valencia. ORCID: 0000-0001-9914-2970. albert.noguera@uv.es

3 El 26 de junio de 1978, la ANPP acordó reformar el artículo 10, inciso a) de la Constitución, a los efectos de que en lo sucesivo la Isla de Pinos pasara a llamarse Isla de la Juventud.

4 Ley de reforma constitucional, de 12 de julio de 1992.

${ }^{5}$ Ley de reforma constitucional, de 26 de junio de 2002. 


\section{TRANSFORMACIONES SOCIO-ECONÓMICAS Y PROCESO CONSTITUYENTE MATERIAL EN CUBA (1991-2018)}

La Constitución de 2019 no es nada más que la concreción jurídico-formal de un proceso constituyente material que viene refundando las relaciones económicas y sociales de la isla desde inicios de la década de los 90, con la caída del campo socialista y el inicio del denominado período especial.

La expresión Proceso Constituyente puede tener varios significados. No es lo mismo «constituir» una comunidad política que elaborar un documento legislativo específico llamado Constitución ${ }^{6}$.

En el primer caso, al que podemos referirnos como proceso Constituyente material, estamos ante un proceso orientado a refundar o a modificar aspectos sustanciales de las relaciones políticas, económicas, sociales y culturales, incluidas las jurídicas. Como describe A. Kalyvas ${ }^{7}$, esta noción de proceso Constituyente material se remonta al propio derecho romano, el verbo constituir proviene del latín y significa crear, establecer, o fundar junto a otros. En el derecho público romano, el verbo constituir designaba una práctica legislativa muy específica: aquella que permitía establecer o alterar las leyes e instituciones fundamentales de la República. En su forma jurídica de rei publicae constituendae aludía al poder para iniciar cambios legales radicales. El título de constitutor, remitía a aquel que ejercía el poder y la autoridad de reformar y trasnformar. Solo tras el colapso de la República, el poder de constituir vino a designar las decisiones judiciales, los decretos y las leyes adoptados por el Emperador (constitutio) $^{8}$.

En el segundo caso, al que nos referimos como proceso Constituyente formal, hace referencia a un proceso más concreto y restringido que tiene como propósito aprobar una Constitución o texto que garantice derechos y regule la organización de los poderes del Estado. Esta noción de proceso Constituyente aparece con la gestación del constitucionalismo revolucionario del siglo XVII y XVIII ${ }^{9}$.

Lo que vamos a demostrar, a continuación, es como, desde la década de los 90 en adelante, viene produciéndose en Cuba un proceso Constituyente material que acaba formalizándose en la Constitución de 2019 como expresión jurídico-formal del mismo.

Desde inicios de los 90 hasta la actualidad, podemos distinguir dos fases distintas de transformaciones: el peridodo especial y la reforma constitucional de 1992, y las transformaciones de la última década (2006-2018). La división entre ambas fases viene dada por el cambio en la dirección política del país de Fidel a Raúl Castro Ruz.

${ }^{6}$ G. PISARELLO, «Democracia y proceso constituyente: el regreso de un vínculo», en R. MARTÍNEZ (ed.), Teoría y práctica del Poder Constituyente, Tirant lo Blanch, Valencia, 2014.

A. KALYVAS, «Constituent Power: A Conceptual History», ponencia presentada en el seminario organizado por Proyecto Trajectories of Modernity en la Universidad de Barcelona, 11 de diciembre de 2012.

${ }^{8}$ G. . PISARELLO, «Democracia y proceso constituyente: el regreso de un vínculo», Op. cit., p. 35.

9 Ibid. 


\section{II.I. El Período Especial y la Ley de Reforma Constitucional de 12 de julio de 1992}

La inserción de Cuba, en 1971, en el mercado económico socialista internacional le proporcionó un trato favorable ${ }^{10}$. Sin embargo, el alto grado de integración económica alcanzado entre los países miembros del CAME, hacía del comercio exterior en estos países la base de la eficacia económica considerada en su conjunto. Esto provocó que el desplome vertiginoso del campo socialista en 1989 y en consecuencia, la desaparición repentina para Cuba del orden internacional al que se encontraba orgánicamente articulada, se tradujera en una profunda crisis para su economía, la cual fue profundizada con el recrudecimiento del bloqueo norteamericano. A las ya existentes medidas de coacción de EEUU sobre terceros países para que cortaran todo tipo de relaciones con Cuba, se sumó ahora la Cuban Democracy Act, conocida como Ley Torricelli, de 23 de octubre de 1992, y la Ley de Libertad Cubana y Solidaridad Democrática, conocida también como Ley Helms-Burton, de 12 de marzo de 1996. ${ }^{11}$

En este contexto, la introducción de reformas para hacer frente a la fuerte crisis económica empieza a partir de la celebración del IV Congreso del PCC, en octubre de 1991, y tuvo su centro jurídico en la Ley de Reforma Constitucional de 12 de julio de $1992^{12}$, que constituye la base jurídica sobre la que desde este momento se articulará la adaptación de la Cuba socialista al nuevo orden mundial ${ }^{13}$. En el sentido económico, la reforma jurídica introduce, básicamente, cambios: 1) en las formas de propiedad; y, 2) la regulación del comercio exterior.

\section{II.I.1. Cambios en las formas de propiedad}

La Constitución de 1976 reconocía como forma principal de propiedad, la propiedad socialista (art. 14). Ésta podía adoptar tres formas distintas: la más importan-

${ }^{10}$ Vid. A. ALONSO, «La economía cubana: los desafíos de un ajuste sin desocialización», Cuadernos de Nuestra América, Vol. IX. Núm. 19, Julio-Diciembre de 1992.

11 Vid. C. GARCÍA VALDÉS, «La economía cubana en los 90: transformaciones en la economía socialista», en VV.AA. Economía: Análisis, propuestas, alternativas, Ed. Ciencias Sociales, La Habana, 1998, p. 14, nota 15$)$.

${ }^{12}$ La reforma supuso la adición al texto constitucional de tres capítulos nuevos (Extranjería; División político-administrativa; y, estado de Excepción) y la modificación de 77 artículos que de un total anterior de 141 se redujeron a 137 (Vid. J. ESCALONA, «En torno a la Ley de reforma Constitucional», Revista Cubana de Derecho, UNJC, Núm. 8, Octubre-Diciembre 1992; M. BURGOS, «El derecho en Cuba socialista. Reflexiones desde perspectivas crítico-dialécticas», en B. BERNAL GÓMEZ (coord.), Cuba hoy: ¿perspectivas de cambios?, Instituto de Investigaciones Jurídicas (IIJ)-UNAM, México, 2011; M. PRIETO, «La reforma a la Constitución cubana de 1976», en M. PRIETO Y L. PÉREZ HERNÁNDEZ (comps.), Temas de derecho constitucional cubano, Félix Varela, La Habana, 2000).

13 La embergadura de los cambios introducidos por la reforma constitucional de 1992 generó un interesante debate en la isla acerca de si debía hablarse de una simple reforma de la Constitución de 1976 o de un nuevo texto constitucional, debido a la magnitud de los cambios. Sobre este debate, vid: «Documentos», Cuadernos Nuestra América, Vol. 20, julio-diciembre de 1993; H. AZCUY, « ¿Reforma constitucional o nueva Constitución?, ponencia en Seminario Interregional, CEA, La Habana, 1994. 
te, que era la propiedad estatal, integrada por los bienes colectivos que conforman el patrimonio del Estado; la propiedad cooperativa ${ }^{14}$; y la propiedad de las organizaciones políticas, de masas y sociales.

Además, la Constitución permitía también algunas formas de propiedad individual: la propiedad de los pequeños agricultores sobre las tierras y demás bienes agropecuarios (Art. 19) y la propiedad personal (Art. 21). Dentro de ésta última incluimos también la propiedad sobre los medios e instrumentos de trabajo personal o familiar que no se empleen para explotar trabajo ajeno, sobre la que se fundamenta la actividad por cuenta propia.

A partir de 1992 la reforma introduce algunos cambios en los preceptos constitucionales que regulan la materia. Entre ellos, destaca la constricción en el art. 14 de la posesión exclusiva del Estado sobre todos los medios de producción a sólo aquellos medios «fundamentales» de producción. Y el reconocimiento en el art. 15, aunque sea usando una excepción autorizante a la formulación negativa general, de posibilidades de transmisión parcial o total de éstos medios a personas naturales o jurídicas.

Tales cambios abrieron un espacio, en la economía cubana, para el desarrollo de la propiedad mixta. El art. 23 reconoció, explícitamente, la propiedad de la empresa mixta, sociedades y asociaciones económicas que se constituyan conforme a la ley. E, incluso, fijó la posibilidad, si en algún momento futuro el Consejo de Ministros o su Comité Ejecutivo lo considerase oportuno, de una propiedad íntegramente privada ${ }^{15}$. No obstante, tanto el Decreto-Ley 50/82 como la Ley 77/95, limitaron el alcance de la preceptiva constitucional al capital procedente del exterior, excluyendo la posibilidad de formación de una propiedad privada nacional ${ }^{16}$.

${ }^{14}$ La propiedad cooperativa está integrada por los bienes que sus miembros aportan, y constituye una nueva forma de colectivización que destina su producción no sólo al beneficio de los cooperativistas, sino también al desarrollo de la producción agropecuaria en general. Esta característica esencial no la convierte en antagónica de la propiedad estatal socialista, pues tienen en común que los medios de producción son de carácter social, las relaciones personales son de colaboración y ayuda mutua y el fin en ambos es el mismo: solventar las múltiples demandas sociales. (F. ÁLVAREZ TABÍO, Comentarios a la Constitución Socialista, Editorial Pueblo y Educación, La Habana, 1989, p.83).

15 Antes de este reconocimiento constitucional, la posibilidad de creación de empresas mixtas o de contratos de asociación económica internacional como modalidad de inversión extranjera, había estado ya prevista, de manera excepcional, por el Decreto-Ley No. 50 de 1982. Sin embargo, la confusión sobre la constitucionalidad o inconstitucionalidad del Decreto-Ley no otorgaba al inversionista foráneo certidumbre y seguridad para la ejecución de sus proyectos económicos y su aplicación práctica fue muy poco relevante (C. GARCÍA VALDÉS, La economía cubana e los años 90: transformaciones en la economía socialista, Op. cit. p. 40). Es a partir de 1992 cuando este instrumento legal empieza a regir dentro de un marco de clara constitucionalidad que se produce un importante incremento de la inversión suscrita por capital extranjero (Vid. J. CARRANZA, L. GUTIERREZ y P. MONREAL, Cuba: la reestructuración económica. Una propuesta para el debate, Ed Ciencias Sociales, La Habana, 1995).

16 En el año 1996 existían en Cuba 260 Asociaciones Económicas Internacionales (éstas comprenden empresas mixtas y contratos de asociación económica internacional) de más de 50 países. Por el número de AEI los principales socios eran: España, Canadá, Francia, Italia, México, Holanda y Reino Unido. Tienen importancia también las asociaciones con países de América Latina como Argentina, Chile y Venezuela. Los sectores más importantes de inversión extranjera eran: el turismo con más de 40 
Con respecto a la agricultura, la reforma no implicó un cambio en las formas de propiedad de la tierra. En esos momentos, la propiedad estatal abarcaba aproximadamente el $82 \%$ de la superficie total de la tierra cultivable del país, la propiedad cooperativa (Cooperativas de Producción Agropecuaria) ocupaban el $8 \%$ y la propiedad privada de los pequeños agricultores (Cooperativas de Crédito y Servicios o miembros de Asociaciones Campesinas) el $10 \%{ }^{17}$. Ahora bien, sí que se produjeron transformaciones con respecto a la gestión de la más importante de estas formas, la propiedad estatal de la tierra.

A partir de 1993 las grandes extensiones de tierra que ocupaban las granjas o empresas agrícolas del Estado, fueron fragmentadas mediante el Decreto-Ley No.142, de septiembre de 1993, en pequeñas formas de producción cooperativa denominadas Unidades Básicas de Producción Cooperativa (UBPC). Estas se caracterizan por el hecho de que la propiedad jurídica de la tierra continua siendo del Estado que la cede a los productores asociados en usufructo gratuito por tiempo indefinido, pero ahora los productores asociados cooperativizan o son dueños del producto y sus ganancias. En cuanto a los medios de producción, los productores los comprarán a crédito al Estado. ${ }^{18}$

asociaciones y 38 contratos de administración; la minería que incluye la explotación del petróleo y comprendía 50 asociaciones. Se habían constituido también, asociaciones en la producción de textil, cuero, perfumería, artículos de aseo personal, jugos de frutas, cerveza y otras. Existían cinco asociaciones relacionadas con el cítrico y otra en la producción y comercialización del tabaco (ICEX, Cuba. Guía de negocios, Madrid, 1999, pp. 33-47). Además, se adoptaron tres acuerdos de mayor volumen de inversión mediante empresas mixtas en las telecomunicaciones y el procesamiento y comercialización del níquel (G. GOMEZ, Cambios y reformas: principales momentos comparativos entre China, Vietnam y Cuba, en VV.AA., Economía: análisis, propuestas, alternativas, Op. cit. pp. 60-62). En 1997 el número de AIE es de 317 y al concluir el año se estudiaban más de 120 proyectos de asociación ( Cuba. La economía al cierre de 1997», Revista Cuba Socialista. Núm. 9, La Habana, 1998, p. 46). En el año 2000, se concertaron 31 negocios entre empresas mixtas y contratos de asociación. En total, desde el inicio del proceso de apertura hasta el 2001, el monto de inversión directa contratada es de alrededor 5.000 millones de dólares (J. TRIANA, «La transformación económica en el socialismo», Academia. Revista del Colegio de Ciencias Sociales y Humanidades de la Universidad de La Habana, Núm. 1, 2001, p. 23).

${ }_{17}$ Ministerio de la Agricultura e Informe de Carlos Lage al V Pleno del Comité Central del PCC. 23 de abril de 1996, La Habana. Citado en: A. NOGUERA, Derecho y hegemonia. Un estudio socio-jurídico de la Cuba actual, Ediciones Cooperativas, Buenos Aires, 2007, p. 265.

18 El debate teórico sobre la naturaleza jurídica de esta forma organizativa, las UBPC, sus posibilidades y limitaciones, se reflejó desde sus inicios. Según el punto de vista de los modelos cooperativos, se considera que su creación constituye un rescate del cooperativismo estatal; con un carácter híbrido, por su dualismo funcional y estructural. Por su funcionamiento, se sitúa entre una unidad comercial y una unidad técnico-productiva; y por su estructura está a medio camino entre la empresa estatal y una verdadera cooperativa. Por otra parte, varios especialistas consideran que su carácter de cooperativa solo reside en su producción cooperada. En cuanto el sujeto que se integra a las UBPC, algunos lo definen por su pertenencia a una cooperativa estatal, por el medio estatal del que proviene y su relación con la propiedad de los principales medios de producción. Otros criterios caracterizan a este sujeto a partir de su participación en la gestión. (Sobre ello, vid. N. PÉREZ y D. ECHEVARRÍA, Participación y producción agraria en Cuba: las UBPC, Revista TEMAS, Núm. 11, Julio-septiembre, La Habana, 1997, p. 71; y, A. FERNÁNDEZ PEISO, El fenómeno cooperativo y el modelo jurídico nacional. Propuesta para la nueva base jurídica del cooperativismo en Cuba, Resumen de la tesis en opción al grado de Doctor en Ciencias Jurídicas, Universidad de La Habana, 2005). 
Sin embargo, las UBPC tenían como único comprador al Estado que además, planificaba los niveles de entrega y fijaba los precios. La imposibilidad de acceso directo al mercado con excedentes hacía que los trabajadores agrícolas ahora constituidos como propietarios socialistas ${ }^{19}$, continuaran siendo en la práctica asalariados estatales y por lo tanto el poder de estímulo de la medida era muy limitado. Durante el primer año de su creación, el 1993, el $59 \%$ de las UBPC no cañeras proyectaban pérdidas para 1994 (30,6 millones de pesos) ${ }^{20}$.

Eso fue una de las causas que llevó para 1994 mediante el Decreto No.191 del Consejo de Ministros emitido el 19 de septiembre y Resolución Conjunta de los Ministros de Agricultura y Comercio Interior de 20 de septiembre, a la apertura de los Mercados Agropecuarios, donde pueden concurrir con sus excedentes todos los agentes vinculados a la producción agropecuaria y los precios se determinan por la oferta y la demanda. Se introdujeron por tanto, mecanismos de mercado y flexibilización de la comercialización en la agricultura nacional.

Finalmente y para terminar con el punto referente a las formas de propiedad, en 1993 por cuanto el desarrollo y organización de la economía nacional imposibilitaba que las empresas o unidades presupuestadas estatales pudieran asegurar determinados servicios y productos necesarios para la población, que de hecho ya se estaban prestando en la economía sumergida, se aprueba el Decreto-Ley No. 141 y la Resolución No.1 del Comité Estatal de Trabajo y Seguridad Social - Comité Estatal de Finanzas (CETSS-CEF) de 8 de septiembre. Esta regulación reconoció el trabajo por cuenta propia como una alternativa de empleo fundamental en 115 actividades para una parte de la población ${ }^{21}$. Los precios de estos servicios o productos se establecerán a partir de la relación oferta-demanda y en el tipo de moneda acordada por quienes participen en la transacción.

II.I.2. La regulación del comercio exterior y la despenalización de la divisa

Hasta 1992 la actividad de comercio exterior estaba controlada en su totalidad por el Ministerio de Comercio Exterior (MINCEX) y realizado en gran medida por

19 El concepto de propietarios socialistas es utilizado por V. FIGUEROA, «El nuevo modelo agrario en Cuba bajo los marcos de la reforma económica». En VV.AA. Desarrollo rural y participación. Ediciones de la Universidad de La Habana. 1996.

20 Ver Boletín de Información Económica, IPS, 30 de septiembre de 1994.

21 Antes de 1993, el Decreto-Ley No. 14 de 3 de julio de 1978 había abierto la posibilidad de realizar actividades laborales por cuenta propia en aquellos ámbitos que la economía nacional no podía cubrir. Esta legislación pero, establecía unos límites muy estrechos. Además, por la Resolución Conjunta No. 14 de 1982 del CETSS y el CEF se prohibía el ejercicio de estas actividades a los graduados de nivel superior y técnico medio — excepto cuando se demuestre la imposibilidad de encontrar empleo estatal - y a los dirigentes de entidades estatales. Tales medidas adoptaron un carácter aún más restrictivo con el proceso de rectificación iniciado en 1986 (A. NOGUERA, Derecho y hegemonía. Un estudio socio-jurídico de la Cuba actual, Op. cit., p. 120). 
empresas de este organismo. La Constitución establecía «el comercio exterior es función exclusiva del Estado» (art. 18). Con la reforma constitucional de este art. 18, aunque el control y dirección sobre el comercio exterior continua siendo monopolio estatal, ahora se permitió que esta actividad fuera asumida también directamente por ciertas sociedades mercantiles no necesariamente pertenecientes a organismos estatales (empresas de capital mixto; representaciones de firmas extranjeras; etc.).

El conjunto de estas transformaciones, tanto los cambios en las formas de propiedad como en la regulación del comercio exterior, produjeron un aumento en la presencia de empresarios extranjeros y de turistas en la isla que llevó consigo la aparición de una red comercial en divisa destinada a la población no nacional. Pero también, la disposición creciente de divisas en manos de la población, ya sea por ingresos en concepto de propinas o regalos recibidos por trabajadores cubanos en empresas extranjeras o vinculadas al turismo, por negocios ilegales de sectores de la ciudadanía con turistas o empresarios, y principalmente, por remesas familiares exteriores en dólares. Se estima que entre 1989 y 1996 se ingresaron en el país por concepto de remesas familiares alrededor de 3.000 millones de dólares ${ }^{22}$.

Ésta situación trajo como principal consecuencia que el gobierno cubano aprobase en 1993 el Decreto-Ley No.140 de despenalización de la tenencia de divisas, por el que se legalizó la tenencia y operación en divisas en todo el territorio nacional para los ciudadanos cubanos.

Se creó, en consecuencia, en el plano económico interno, una economía de carácter dual con la coexistencia de dos sectores que tienen una organización, actores y lógicas diferentes. Junto al sector tradicional constituido por empresas íntegramente estatales, que opera en moneda nacional (peso) y se rige por mecanismos de planificación, se creó un sector nuevo o emergente, integrado principalmente por Sociedades Anónimas de inversión conjunta, Sociedades Anónimas cubanas o representaciones de firmas extranjeras, que opera en divisa, primero en dólares y a partir de 2004 en Pesos Cubanos Convertibles (CUC), y se rigen con precios de oferta y demanda. Este sector ha llegado hoy a adquirir el predominio en la mayoría de aspectos de la actividad económica.

\section{II.II. Retiro de Fidel Castro y transformaciones de la última década (2006-2018)}

Ubicaremos el inicio de este segundo período de transformaciones con el abandono, en julio de 2006, de la dirección política del país por parte de Fidel Castro. A partir de este momento, y con Raúl Castro al frente, se activa otro paquete de transformaciones del modelo socio-económico, plasmadas en múltiples modificaciones a leyes, decretos-leyes, decretos y reglamentos.

${ }^{22}$ Vid. H. MARQUETTI, «La economía del dólar: balance y perspectivas», Revista TEMAS, Núm. 11, La Habana, Julio-Septiembre de 1997. 
Como afirma Mylai Burgos ${ }^{23}$, dichas transformaciones han tenido tres momentos clave: sus inicios, desde 2006 con mayor consolidación a partir de 2008. Posteriormente, el VI Congreso del PCC, en abril de 2011, y los lineamientos de políticas económicas y sociales surgidos de él que tuvieron un proceso previo de discusión participativa en el seno de la sociedad. Y, por último, el restablecimiento de las relaciones diplomáticas con Estados Unidos, a partir de 2015.

Aunque las medidas adoptadas son muchas ${ }^{24}$, centraremos nuestro análisis en tres bloques: 1. Las transformaciones en la propiedad agraria y la reforma de la Ley de vivienda; 2. Las reformas en el trabajo y la seguridad social; y, 3. La Ley de inversión extranjera de 2014.

II.II.1. Transformaciones en la propiedad agraria y la reforma de la Ley de vivienda

Una de las novedades introducidas, a través del Decreto-Ley núm. 259/2008, emitido por el Consejo de Estado, fue la entrega en usufructo a persones naturales o jurídicas de tierras ociosas para su producción agropecuaria ${ }^{25}$. El objetivo de esta medida fue la concesión de derechos a los campesinos para produir en mejores condiciones laborales y de sustento básico, así como mejorar la satisfacción de necesidades de alimentación de la población en general por el aumento de la producción alimentaria, lo que implica una disminución de los precios en el mercado, además de una mayor variedad y calidad.

El límite máximo a entregar a personas naturales sin tierras es de 13.42 hectáreas. En el caso de quienes posean tierras, en propiedad o usufructo, podrán incrementarlas hasta completar 40.26 hectáreas (Art. 6). El período del usufructo es de hasta diez años y prodrá ser prorrogado sucesivamente por términos de hasta diez años (Art. 2). El Decreto obliga al usufructuario a trabajar personalmente la tierra concedida, así como la posibilidad de construir una vivienda e instalaciones de trabajo para el aprovechamiento de las labores allí realizadas.

Las personas jurídicas autorizadas para la entrega de tierra son granjas estatales, UBPC, cooperativas de producción agropecuaria, cooperativas de créditos y servicios, entidades estatales no agropecuarias y otras instituciones que quisieran destinar las tierras para el autoabastecimiento de sus trabajadores, además de otras que

${ }^{23}$ M. BURGOS, «Análisis crítico constitucional de los cambios socio-jurídicos en la Cuba actual», Revista Direito E Práxis, Vol. 08, Núm.4, Rio de Janeiro, 2017, p. 3179.

${ }^{24}$ Vid. M. ESPINA, J.L. DOMÍNGUEZ, O.E. PÉREZ VILLANUEVA Y L. BARBERÍA, LORENA (coords.), Desarrollo económico y social en Cuba. Reformas emprendidas y desafíos en el siglo XXI, Fondo de Cultura Económica, México, 2012.

25 Desarrollado por el Decreto Núm. 282/2008. Reglamento para la implementación de la entrega de tierras ociosas en usufructo. 
se autoricen excepcionalmente (Art. 11). A éstas, se les otorga la tierra por un período de veinticinco años prorrogable a un período igual (Art. 2) ${ }^{26}$.

Esta regulación ha sufrido diversas modificaciones. En 2012, este Decreto-Ley fue sustituido por el Decreto-Ley núm 300/2012, de entrega de tierras estatales en usufructo. A la vez que en 2013, el de 2012 fue también modificado por el Decreto-Ley núm. 311/2013 modificativo del anterior.

Las reformas al primer Decreto-Ley van en el sentido de ampliar la cota máxima de tierra a entregar ${ }^{27}$. Asimismo, teniendo en cuenta que la mayoría de tierras han sido entregadas a campesinos individuales ${ }^{28}$, para evitar procesos individualistas de producción y favorecer la asociación colectiva, desde 2012, se establece que el usufructuario deberá estar vinculado, mediante una relación contractual, a una granja estatal con personalidad jurídica, una unidad básica de producción cooperativa (UBPC), o una cooperativa de producción agropecuaria (CPA); ubicadas en una proximidad de hasta cinco kilómetros.

Conjuntamente con las transformaciones en la propiedad agraria, otro cambio importante en la isla ha sido el de la autorización de la compraventa de viviendas, mediante el Decreto-Ley 288/2011 del Consejo de Estado, de 28 de octubre, modificativo de la Ley General de Vivienda núm. 65/1988, acompañado de seis resoluciones complementarias para aplicar la ley ${ }^{29}$.

Hasta este momento, estaban permitidas las permutas o intercambios, pero no la compraventa de viviendas. La nueva reforma autoriza la compraventa de viviendas por parte de ciudadanos y extranjeros residentes permanentes en la isla y permite a los compradores y vendedores fijar libremente el precio. La permuta subsiste, pero ahora es legal el pago de una compensación que antes se hacía de forma ilegal. Con el fin de evitar la concentración de propiedades, el Decreto-Ley limita la posesión de propiedades a dos, una residencia permanente y otra de veraneo o descanso ${ }^{30}$.

${ }^{26}$ En julio de 2009 se habían realizado 110 mil solicitudes de entrega de tierras ociosas en usufructo y se aprobaron cerca de 82 mil, abarcando unas 690 mil hectáreas que implicaban el 39\% del área de tierras ociosas del país («Entrevista a Orlando Lugo Fonte, Presidente de la Asociación Nacional de Agricultores Pequeños (ANAP)», Periódico Trabajadores, 22 de junio 2009).

27 Se mantiene la solicitud inicial en un área de 13,42 hectáreas, pero más tarde esta puede extenderse hasta 67,10 hectáreas. Anteriormente se aprobaban hasta 40,26 hectáreas.

${ }^{28}$ Hasta 2012 se habían otorgado 1.523.000 hectáreas. Habían sido procesadas 197.000 solicitudes, de las cuales 174.271 ya habían sido aprobadas. Entre el total de solicitudes, 2.700 corresponden a personas jurídicas y el resto a personas naturales. De estas últimas, entre $9 \%$ y $10 \%$ son mujeres, $23 \%$ tiene experiencia en la agricultura, lo cual arroja $77 \%$ sin dominio de la actividad. Más de $35 \%$ de los usufructuarios tenían entre 20 y 35 años ( «Nuevas regulaciones sobre la entrega de tierras en usufructo», Opciones. Semanario económico y Financiero de Cuba, 26 de octubre de 2012).

29 Resolución 85/11 del Banco Central de Cuba; Resoluciónes 342 y 343/11 del Instituto Nacional de la Vivienda; Resolución 351/11 del ministerio de Finanzas y Precios; y, Resolución 270/11 del Ministerio de Justicia.

${ }^{30}$ D. CAVE, «Cuba to allow buying and selling of property, with few restrictions», The New York Times, 4 de novembre de 2011; C. MESA-LAGO, «Las reformas de Raúl Castro y el congreso del Partido Comunista de Cuba: avances, obstáculos y resultados», Documentos CIDOB América Latina, núm. 35, 2011, p. 8. 


\section{II.II.2. Las reformas en el trabajo y la seguridad social}

Uno de los cambios con más trascendencia en este período fue el anuncio por parte de Raúl Castro, siguiendo el punto 169 de los lineamientos de la política económica y social del VI Congreso del PCC ${ }^{31}$, de la necesidad, por cuestiones de eficiencia del sector estatal, de una reordenación laboral del país consistente en el desplazamiento de 500 mil trabajadores del sector público hacia el sector privado (arrendamiento o usufructo, las cooperativas y el trabajo por cuenta propia), en un plazo no mayor a seis meses entre finales de 2010 y el primer trimestre de 2011.

Para facilitar esta transición, se llevaron a cabo reformas en la legislación reguladora del trabajo por cuenta propia. El mismo 2010 se aprobó la Resolución núm. 32/2010 del Ministerio de Trabajo y Seguridad Social, complementada con un sinfín de normas ${ }^{32}$. Un año más tarde, fue sustituida por la Resolución Núm. 33/2011, de la Ministra de Trabajo y Seguridad Social, "Reglamento del ejercicio del trabajo por cuenta propia..

El objetivo de todas estas reformas fue ampliar y flexibilizar las actividades por cuenta propia. Entre otras medidas, se amplían de 178 a 181 las actividades que se

31 Este punto establece: «Desarrollar un proceso de reordenamiento laboral en el país que, bajo el principio de la idoneidad demostrada, contribuya a eliminar las plantillas infladas y los tratamientos paternalistas, para estimular la necesidad de trabajar y reducir los gastos de la economía y el Presupuesto del Estado».

32 Decreto-Ley No. 275 de 30 de septiembre de 2010, «Modificativo del DecretoLey No. 171/97, Del régimen de arrendamiento de viviendas, habitaciones o espacios»; Resolución No. 305 de 7 de octubre de 2010, del Presidente del Instituto Nacional de la Vivienda, que aprueba el Reglamento del arrendamiento de viviendas, habitaciones y espacios; Resolución No. 399 de 7 de octubre de 2010, del Ministro del transporte, que aprueba el Reglamento de la licencia de operación de transporte para personas naturales; Resolución No. 750 de 7 de octubre de 2010, del Ministro de la Agricultura, que regula la contratación de trabajadores agrícolas asalariados permanente y trabajadores agrícolas eventuales; Resolución No. 33 de 7 de octubre de 2010, de la Ministra de Trabajo y Seguridad Social, que regula la contratación por las Cooperativas de créditos y servicios de trabajadores permanentes asalariados para que trabajen junto a los Agricultores pequeños y por los agricultores pequeños, de los servicios de trabajadores agropecuarios eventuales que ejercen el trabajo por cuenta pròpia; Resolución No. 34 de 7 de octubre de 2010, de la Ministra de Trabajo y Seguridad Social, que aprueba el procedimiento para la afiliación al régimen especial de seguridad social para los trabajadores por cuenta pròpia; Decreto-Ley No. 277 de 30 de septiembre de 2010, «Modificativo del Decreto-Ley No. 169, de las normas generales y de procedimientos tributarios»; Resolución No. 286 de 7 de octubre de 2010, de la Ministra de Finanzas y Precios, que aprueba las normas relativas al pago de los impuestos sobre los ingresos personales, las ventas, los servicios públicos, por la utilización de la fuerza de trabajo, y las referentes al pago de la contribución a la seguridad social por los trabajadores por cuenta pròpia; Resolución No. 287 de 7 de octubre de 2010, de la Ministra de Finanzas y Precios, que establece el impuesto sobre servicios públicos, en lo concerniente al arrendamiento de viviendas, habitaciones y espacios; Resolución No. 289 de 7 de octubre de 2010, de la Ministra de Finanzas y Precios, que establece el pago en pesos cubanos del impuesto sobre documentos, para trámites de inscripción y reinscripción en el registro de contribuyentes, de los trabajadores por cuenta propia, con independencia de la moneda en que operan Decreto-Ley No. 274 de 30 de septiembre de 2010, Modificativo del Decreto-Ley No. 174/97, «De las contravenciones personales de las regulaciones del trabajo por cuenta propia». 
pueden realizar, se establece la posibilidad de la utilización de fuerza de trabajo contratada para todas las actividades permitidas, aumentan de 20 a 50 el número de sillas de que pueden disponer los elaboradores-vendedores de alimentos y bebidas mediante servicio gastronómico y también se exonera del pago del impuesto por la utilización de la fuerza de trabajo a los que contrataban hasta 5 trabajadores. Además, se autoriza la concesión de créditos bancarios para los cuentapropistas en aras a que puedan invertir en sus negocios, se introducen cambios en el régimen de tributación y se fija, mediante el Decreto-Ley núm. 278/2010 de 30 de septiembre, un régimen especial de seguridad social para los trabajadores por cuenta propia a través del que se les ofrece protección ante la vejez, la invalidez parcial o permanente y, en caso de muerte a su familia, así como a la trabajadora en ocasión de la maternidad. ${ }^{33}$

Aunque no se ha logrado desplazar hacia el sector privado a toda la cantidad de trabajadores prevista, sí se ha producido un fuerte incremento del mismo. Una de las principales actividades que ha crecido de manera desmesurada ha sido la de arrendamiento de habitaciones o viviendas turísticas. Para ello, se eliminó el exceso de controles existentes. De los 17 documentos que se exigían antes, en estos momentos solo se requieren tres: la propiedad de la casa, el sello y un escrito de solicitud.

A la vez, se ha aprobado un nuevo Código del Trabajo. En la reunión del 13 de diciembre de 2012 de la VII Legislatura de la Asamblea Nacional fue presentado el Anteproyecto de Ley de Código de Trabajo y fue definitivamente aprobado el 20 de diciembre de 2013. Éste supone la modificación de 101 artículos, la inclusión de 28 nuevas normativas y la total reelaboración del Capítulo II, referente a las organizaciones sindicales, el artículo 2 acerca de los principios que rigen el Derecho del trabajo y la modificación parcial de su Capítulo XV referente a las autoridades de trabajo.

Por primera vez, se desarrollan las relaciones laborales en el sector privado, en una sección de capítulo enteramente dedicada a ello (Sección primera, Capítulo VII), que regula las «Relaciones de trabajo entre personas naturales» y establecen los «derechos mínimos que debe garantizar el empleador».

Aunque se mantienen gran parte de las prácticas y técnicas de ordenación laboral existentes en el anterior Código ${ }^{34}$, el nuevo introduce fuertes elementos de flexibilidad laboral. El comunicado del secretariado nacional de la Central de Trabajadores de Cuba (CTC), de 13 de septiembre de 2010, establecía: «se modificará el actual tratamiento laboral y salarial (...) pues ya no será posible aplicar la fórmula de proteger o subsidiar salarialmente de forma indefinida a los trabajadores».

En este sentido, y para mencionar algunos ejemplos, el nuevo Código elimina la redacción del viejo según la cual «el contrato de trabajo por tiempo determinado debe

33 A.F. ANTÚNEZ SÁNCHEZ, J.M. MARTÍNEZ CUMBRERA Y J.L. OCAÑA BÁEZ, «El trabajo por cuenta propia. Incidencias en el nuevo relanzamiento en la aplicación del modelo económico de Cuba en el siglo XXI», Nómadas. Revista Crítica de Ciencias Sociales y Jurídicas, Núm. Especial América Latina, 2013.

34 Sobre éste, vid. G. FERRIOL, «El derecho laboral en Cuba. Fundamentos, actualidad y perspectivas», Alegatos, Núm. 72, México, 2009, pp. 29-66. 
expresar la fecha de su terminación, que no puede exceder de tres años», permitiendo que los contratos temporales por tiempo determinado no se encuentren sometidos a límite temporal máximo de duración, lo que dota de notable inseguridad jurídica a los trabajadores contratados bajo esta modalidad.

Además, se extiende la duración del período de prueba. De acuerdo con la antigua ley, éste no podia exceder de 30 días, en el actual Código del Trabajo éste puede abarcar «entre treinta y hasta ciento ochenta días» (art. 32). Asimismo, los nuevos arts. 36, 37 y 38 utilizan el indeterminado concepto de «idoneidad demostrada» para posibilitar la terminación del contrato de trabajo por iniciativa del empleador.

Cambian también las condiciones para los llamados trabajadores disponibles. Se denomina así a quiénes se amortizaba su plaza y se le brindaba la posibilidad de reubicarse en otra plaza. Hasta ahora solo se aplicaban procesos de disponibilidad cuando existían ofertas de reubicación de los trabajadores y la ley establecía que los trabajadores que eran despedidos recibían su salario básico completo hasta que fuesen colocados en otro Trabajo. El nuevo Código del Trabajo prevé la figura de trabajadores disponibles que no puedan ser reubicados y reduce la cantidad de dinero a recibir. Ahora el subsidio del $100 \%$, será limitado únicamente a un mes, después del cual el trabajador recibirá un beneficio únicamente del $60 \%$ de su salario básico durante un mes para aquellos que han trabajado hasta 19 años, dos meses para aquellos que han trabajado entre 20 y 25 años, tres meses para aquellos que acumulan entre 26 y 30 años y un máximo de cinco meses para aquellos que han trabajado más de 30 años (Art. 53).

En paralelo a las modificaciones en el Trabajo, se ha llevado a cabo también una reforma del sistema general de Seguridad Social a través de la nueva Ley núm. 195/2008, de 27 de diciembre, desarrollada reglamentariamente mediante el Decreto núm. 283/2009 del Consejo de Ministros, de 6 de abril.

El elemento más cuestionado de la nueva Ley ha sido el retraso de la edad de jubilación para tener derecho a la pensión, que pasa de 55 a 60 años para las mujeres y de 60 a 65 años para los hombres (Art. 22.I.a) ${ }^{35}$. Además, se modifican los requisitos requeridos para optar a una pensión por edad ${ }^{36}$ e introducen diversas modificacio-

35 Sobre la Ley de Seguridad social, vid.: «80 preguntas y respuestas sobre el anteproyecto de nueva ley de seguridad social», Granma, núm. 70, 11 de marzo de 2014; S. LEE, «En vigor Reglamento de la Ley de Seguridad Social», Granma, núm. 129, 9 de mayo de 2009.

36 Se aumenta el tiempo de servicios requerido de veinticinco a treinta años para optar a la pensión por edad en los trabajadores comprendidos en pensión ordinaria Categoría I; en tanto para los comprendidos en Categoría II, se eleva también la edad de jubilación en cinco años y se fija el tiempo de servicios en treinta años como mínimo, manteniendo la condición de haber laborado en trabajos comprendidos en esta categoría no menos de quince años anteriores a su solicitud, o el $75 \%$ del tiempo de servicio requerido para tener derecho a la pensión, si en el momento de solicitarla no se encontraba desempeñando un cargo comprendido en esta categoría. Otro cambio importante es la forma de cálculo de la pensión. La Ley dispone que los cinco años naturales en los que el trabajador haya devengado sus mayores salarios, serán seleccionados dentro de los últimos quince y no diez como estipulaba la ley anterior (J.R. MERCADER, Las últimas reformas laborales en Cuba (2009-2014), Cuba Study Group, Washington DC, 2015, p. 6). 
nes en el sistema de financiación de la Seguridad social, mediante aprobación de la nueva Ley núm. 113/2012 del sistema tributario y el Decreto núm. 308/2012 del Consejo de Ministros que establece el Reglamento de las normas generales y procedimientos tributarios.

En 1962, se suprimió la obligación de cotitzar para los trabajadores asalariados, estableciéndose el principio de contribución exclusiva del empleador. Durante todo este tiempo, los recursos para financiar el conjunto de servicios y prestacions ofrecidas gratuitamente por el Sistema Nacional de Salud y el régimen de asistencia social provenía de las cotizaciones de los empleadores y de las transferencias del Presupuesto General del Estado. Teniendo en cuenta la incapacidad del anterior sistema para financiar la Seguridad social, la nueva Ley tributaria establece un impuesto sobre los ingresos personales de todos los trabajadores (Arts. 16 y 17$)^{37}$.

\section{II.II.3. La Ley de inversión extranjera de 2014}

La Ley núm. 118 de Inversión Extranjera, de 29 de marzo del 2014, ha venido a derogar la Ley núm. 77 de la Inversión Extranjera de 1995. Con caracter previo, el 23 de septiembre de 2013 se publicó el Decreto-Ley núm. 313 «De la Zona Especial de Desarrollo Mariel» que ha sido objeto de desarrollo posterior.

La nueva Ley de Inversión Extranjera persigue establecer las bases jurídicas para atraer y ampliar la inversión extranjera en la isla ${ }^{38}$. La ley establece que la inversión extranjera puede ser autorizada en todos los sectores, con excepción de los servicios de salud y educación a la población, y de las instituciones armadas, salvo en sus sistemas empresariales. También introduce la nueva figura de la «cartera de oportunidades» ${ }^{39}$, una especie de catálogo dirigido a los inversionistas extranjeros en el que se publican, cada año, las oportunidades de inversión en promoción ${ }^{40}$.

A la vez, se regulan garantías para los inversionistas que antes no estaban recogidas, explícitamente, en la ley núm. 77/1995, tales como el hecho de que el Estado cubano garantiza que los beneficios concedidos a los inversionistas extranjeros y a sus inversiones se mantienen durante todo el período por el que hayan sido otorgados, la

37 Con anterioridad a la nueva Ley, la Ley núm. 73/1994 del sistema tributario, de 4 de agosto, ya había establecido un impuesto sobre los ingresos personales de los trabajadores asalariados en su art. 18. Sin embargo, en la práctica, nunca se llegó a aplicar.

38 Sobre ello, vid. O.E. PÉREZ VILLANUEVA, «La inversión extranjera directa en Cuba: necesidad de su relanzamiento", Economía y desarrollo, Vol. 152, núm. 2, La Habana, 2014; O.E. PÉREZ VILLANUEVA, La ruta necesaria del cambio económico, Ciencias Sociales, La Habana, 2013.

39 Vid. Cuba. Cartera de oportunidades de inversión extranjera, 2017-2018: file://C:/Users/USER/ Downloads/Cartera\%20de\%20Oportunidades\%20de\%20Inversin\%20Extranjera\%202017-2018.pdf

40 Con anterioridad a la Ley el CEPEC (Centro para la Promoción de las Exportaciones de Cuba) ya publicaba, incluso, en la página web concebida para ello, ciertas oportunidades de proyectos con inversión extranjera, sin embargo, no existía la figura de la cartera de oportunidades reconocida legalment (R. HERNÁNDEZ FERNÁNDEZ, Ley núm. 118, Ley de Inversión Extranjera, Ediciones ONBC, La Habana, 2015, p. XVI). 
libre transferencia al exterior de sus dividendos y beneficios, la opción de venta en cualquier momento de su parte en la asociación o la existencia de un conjunto de facilidades, excepciones y/o exenciones tributarias. En concreto, es el Capítulo XII sobre el régimen especial de tributación el que atribuye incentivos fiscales para las empresas mixtas y asociaciones económicas internacionales, puesto que aunque aparecen impuestos regulados por la nueva Ley Núm. 113 de 2012, del Sistema tributario, se eximen temporalmente y se reducen de manera significativa los tipos impositivos en muchos casos.

Asimismo, se reconoce la facultad que poseen las empresas mixtas, los inversionistas nacionales y los inversionistas extranjeros partes en contratos de asociación económica internacional, y las empresas de capital totalmente extranjero, de poder abrir cuentas en cualquier banco del Sistema Bancario Nacional, por medio de las cuales efectúan los cobros y pagos que generan sus operaciones según el régimen monetario vigente. Esta última frase no aparecía en un precepto similar de la Ley Núm. 77 y, seguramente, se incluye ahora previendo la próxima unificación monetaria en $\mathrm{Cuba}^{41}$.

Además, la nueva Ley unifica en su texto muchas regulaciones, no incluidas en la Ley 77/1995, que se encontraban dispersas en distintas normas. Por ejemplo, las acciones de control a las modalidades de inversión extranjera fijadas en la Resolución Núm. 27/2003, del Ministerio para la Inversión Extranjera y la Colaboración económica, «Normas relativas a la actividad de supervisión y control de las inversiones extranjeras». O, los mecanismos de solución de determinados conflictos por parte de la Sala de lo Económico del Tribunal Provincial Popular que corresponda, entre los socios de una empresa mixta o entre inversionistas nacionales y extranjeros partes en contratos de asociación económica internacional o entre los socios de una empresa de capital totalmente extranjero, recogidos en el Decreto-Ley núm. 241 de $2006^{42}$.

En resumen, la nueva Constitución no es más que un proceso jurídico-formal que recoge todo el proceso constituyente de carácter material tendente a refundar las relaciones económicas y sociales del sistema cubano que se ha producido desde la caída del campo socialista y durante las últimas casi tres décadas en la isla, mediante las transformaciones descritas.

41 Ibid. p. XIX.

42 En el 2017 funcionaban en Cuba unas 250 empresas en asociación con el Estado cubano, tanto mixtas como en contratos de administración hoteleros, entre otras variantes, y existen negocios en diferentes ramas de la economía, como la minería, entre ellas el petróleo, níquel, bebidas, tabacos, alimentación, etc. Y en la Zona Económica Especial de Mariel (ZEDM) se contaba con 19 usuarios, de ellos 10 de capital $100 \%$ extranjero, 4 empresas mixtas, 4 empresas cubanas y un contrato de asociación económica internacional. A pesar de ello, la participación de los montos de inversión de los capitales extranjeros con respecto a la economía cubana han sido extremadamente bajos, incluso estando por debajo del 0,5\% con respecto al PIB cubano (O.E. PÉREZ VILLANUEVA, «La inversión extranjera directa en Cuba: resultados e importancia», Cuba posible, 10 de enero de 2017, La Habana). 


\section{LA NUEVA CONSTITUCIÓN DE 2019: AVANCES Y DEFICIENCIAS}

Vistos los cambios socio-económico en que se fundamenta la nueva Constitución, detengámonos ahora en ver el procedimiento de aprobación de ésta, así como en un análisis más detallado de algunas de las deficiencias y novedades que introduce. Veremos, en concreto, la cuestión de la supremacía y aplicabilidad directa de la Constitución, la carta de derechos, los mecanismos de participación y control democráticos, la administración territorial y la cuestión de la propiedad y modelo económico.

\section{III.I. El procedimiento de aprobación de la Constitución}

El procedimiento de aprobación de la nueva Constitución ha seguido la siguiente secuencia: $1 .^{\circ}$. Del 20 al 22 de julio de 2018 la ANPP inició el trámite de discusión y aprobación de un anteproyecto de Constitución elaborado por un grupo de trabajo del Buró Político del PCC creado el 13 de mayo de 2013 y una comisión parlamentaria creada el 2 de junio de 2018 para este objetivo; $2 .^{\circ}$. Este anteproyecto fue sometido a una fase de consulta ciudadana, entre agosto y noviembre de 2018 , destinada a la discusión y recojida de propuestas ${ }^{43} ; 3 .^{\circ}$. Después de la incorporación al anteproyecto constitucional de las propuestas ciudadanas que se consideraron procedentes desde el punto de vista jurídico, en diciembre de 2018 la Asamblea Nacional aprobó el proyecto definitivo de Constitución; y, $4 .^{\circ}$. En febrero de 2019 se celebró un referéndum mediante el que la ciudadanía ratificó la Constitución.

Este procedimiento fue críticado por parte de algunos sectores intelectuales de la isla que recriminaron que la reforma no se hiciera por una Asamblea Constituyente participativa, de abajo hacia arriba ${ }^{44}$. El hecho de que el texto fuera redactado primero por el poder constituido y luego sometido a consulta a la ciudadanía, de arriba hacia abajo, permitía al Poder, argumentaron estos sectores, un mayor control sobre todo lo propuesto porque se discute sobre algo ya elaborado y argu-

43 Según datos oficiales, durante el proceso de consulta se realizaron 133.681 reuniones, de las cuales: 79.947 de la población, 45.452 de colectivos de trabajadores, 3.441 de campesinos, 1.585 de estudiantes universitarios, 3.256 de estudiantes de la enseñanza media. De todas ellas se recogieron 1.706.872 intervenciones, 783.174 propuestas de los residentes en Cuba (666.995 modificaciones, 32.149 adiciones, 45.548 eliminaciones, 38.482 dudas) y 2.125 propuestas de cubanos residentes en el exterior (1.150 modificaciones, 350 adiciones, 406 eliminaciones, 219 dudas). [ «Los datos precisos del proceso de consulta popular de la Reforma constitucional fueron dados a conocer en la Asamblea Nacional», Juventud Rebelde, 22 de diciembre de 2018 (disponible en: http://www.juventudrebelde.cu/ cuba/2018-12-22/resultados-del-proceso-de-consulta-popular)]

${ }^{44}$ Sobre ello, vid. M. BURGOS, «El proceso de reforma de la Constitución en Cuba», Rebelión, 31 de julio de 2018. 
mentado previamente, incluso discutido con cierta amplitud en el órgano legislativo de manera pública, y todos los argumentos ya vertidos permean la consciencia colectiva sobre los temas, generando un estado de opinión sobre ellos, lo que propicia el control sobre los mismos.

La justificación, por parte del poder oficial, del procedimiento elegido se basó en argumentos de legalidad y legitimidad.

Respecto a la legalidad, ni la Constitución de 1976 ni el Reglamento de la ANPP determinaban a quien corresponde la iniciativa para la reforma o revisión de la Constitución. En este sentido, autores como Fernando Álvarez Taibo ${ }^{45}$, miembro de la comisión encargada de redactar el anteproyecto de Constitución de 1976, entendieron que debe aplicarse, para el caso, la misma norma constitucional que regula la iniciativa de leyes establecida en el art. 88 de la Constitución del 76, conforme a la cual compete: a los diputados de la ANPP, al Consejo de Estado, al Consejo de Ministros, a las comisiones de la ANPP, a las direcciones nacionales de las organizaciones sociales, al Tribunal Supremo Popular en materia de administración de justicia, a la Fiscalia General de la República en ámbitos de su competencia o a los ciudadanos con un mínimo de 10.000 firmas. Conjuntamente con ello, se alegó también que el art. 137 de la Constitución de 1976 preveía un proceso de rigidez constitucional (procedimiento especial diferente a cómo se modifican las leyes ordinarias y establecido en la mayoría de las Constituciones del mundo en la actualidad) donde las reformas a la Constitución cubana se realizan únicamente por la ANPP, mediante voto nominal (cada diputado debe exponer el motivo de su votación al ejercer el derecho al voto), por votación cualitativa (dos terceras partes de los integrantes del órgano parlamentario), con una cláusula pétrea (inmodificabilidad del sistema político socialista) y referendo popular para algunas temáticas como son la organización estatal y los derechos y deberes ciudadanos, (votación universal de la ciudadanía electoral cubana siendo aprobado por mayoría simple).

Asimismo, también se ha alegado la legitimidad democrática del proceso, ya que como se acordó por el propio órgano parlamentario, se realizó un proceso de discusión popular del anteproyecto por la ciudadanía entre el 13 de agosto y el 15 de novembre de 2018, previsto en el art. 72 del Reglamento de la ANPP ${ }^{46}$, para finalmente, someter a ratificación el texto mediante referendo popular.

45 F. ÁlVAREZ TABÍO, Comentarios a la Constitución socialista, Op. cit., pp. 426-427.

46 Art. 72 Reglamento de la ANPP: «La Asamblea Nacional puede decidir la convocatoria a consulta popular del proyecto en cuestión, previamente al debate para su consideración. En ese caso el Presidente encarga a una Comisión la organización de la discusión popular, lo que se coordina con las organizaciones de masas y sociales, a fin de realizarla. Al término de la discusión, la Comisión comunica los resultados a la Asamblea Nacional por medio del Presidente de esta y hace las recomendaciones pertinentes sobre las sugerencias y proposiciones de modificaciones que se hayan formulado». 


\section{III.II. La supremacía y aplicabilidad directa de la Constitución}

Una de las críticas que los constitucionalistas, en el interior de la isla, venían desarrollando sobre el anterior modelo constitucional era la inexistencia del principio de supremacía constitucional.

Las dos principales representantes de tal crítica han sido Martha Prieto y Lissette Pérez, profesoras de Derecho Constitucional de la Universidad de La Habana. En concreto, proponían la necesidad de avanzar hacia un modelo de Estado Constitucional basado en la recuperación del principio de supremacía y aplicación directa de la Constitución como límite al Poder en defensa de los derechos de los ciudadanos y creación de un órgano jurisdiccional especial, léase Tribunal Constitucional, para ejercer control de constitucionalidad ${ }^{47}$.

Tal como explica M. Prieto ${ }^{48}$, la idea de Estado constitucional se mantuvo durante los primeros 14 años de la Revolución aunque fue, posteriormente, suprimida. Al inicio de la Revolución se enfrentaron dos posiciones, ambas defensoras de la construcción de una nueva sociedad socialista, aunque discrepantes acerca del valor que había de jugar la Ley Fundamental de 1959.

Por un lado, Fernando Álvarez Tabío ${ }^{49}$, entre otros, defendió el principio de supremacía de la Constitución y existencia de control de constitucionalidad que garantizara la subordinación del poder y el resto de normas a la Constitución ${ }^{50}$. De hecho, durante los años siguientes del triunfo revolucionario, aún se conservó la denominada Sala de Garantías Constitucionales y Sociales del Tribunal Supremo conforme a la Ley Fundamental de 1959. En su art.160, ésta definió la competencia

${ }^{47}$ Vid. M. PRIETO, «En pos de la aplicabilidad directa de la constitución cubana de 1976 (un breve comentario)», IUS. Revista del Instituto de Ciencias Jurídicas de Puebla A.C., núm. 21, 2008; M. PRIETO, «Las garantías constitucionales de los derechos fundamentales y la Constitución cubana de 1976», en A. MATILLA (Coord.), La Constitución cubana de 1976: cuarenta años de vigencia, UNIJURIS, La Habana, 2016; M. PRIETO, «Reflexiones en torno al carácter normativo de la Constitución», L. PÉREZ y M. PRIETO (Comps.), Temas de derecho constitucional cubano, Félix Varela, La Habana, 2004; M. PRIETO y L. PÉREZ, «Bases para un proyecto de ley sobre control constitucional», Informe de Investigación «Las Quejas de la Población. 1994-96», Premio CITMA al Diseño de Investigación, 1994 (Inédito, no publicado); M. PRIETO, «El sistema de defensa constitucional cubano», Revista Hispanoamericana de Derecho, año 1, Núm. 2, Universidad de Huánuco, Perú, 2004 y en Revista cubana de Derecho, 2006, pp.25-53; M. PRIETO, «Garantías y Defensa de los Derechos fundamentales de la ciudadanía cubana», Revista El Otro Derecho, Número 17, Vol. 6, No. 2, ILSA, Colombia, 1994, p.113; M. PRIETO, «El Derecho, la Constitución y la interpretación», en L. PÉREZ GALLARDO (coord.), Perspectiva del Derecho cubano actual, Reus, Madrid, 2006, pp.31-97.

48 M. PRIETO, «En pos de la aplicabilidad directa de la constitución cubana de 1976 (un breve comentario)», Op. cit. pp. 193-205.

49 F. ÁLVAREZ TABÍO, El recurso de inconstitucionalidad, Librería Martí, La Habana, 1960, pp. 7-10.

50 En su obra citada, Álvarez Tabío reafirma el valor normativo de la Ley Fundamental de 1959 cuando destacó que el supremo órgano de justicia no podía apartarse de sus normas ni tolerar una ley ordinaria que ofendiere los derechos esenciales consagrados en ella. 
de este órgano de manera idéntica que la Constitución de 1940 en su art. 182. Fue en 1973, cuando el Tribunal de Garantías Constitucionales y Sociales desapareció con la reforma del sistema judicial ${ }^{51}$.

No obstante, por otro lado, en las decisiones del Tribunal Supremo del período mencionado, antes de 1973, se puede encontrar también otra posición opuesta respecto a la supremacía de la Constitución, la que limita su valor jurídico, como ley aplicable o norma de contraste. La Sala de Garantías en algunas sentencias se opuso a la aplicación directa de la misma respecto a algunos preceptos y reclamó la espera de leyes de desarrollo que instrumentarían y permitirían aplicar los contenidos de la Ley Fundamental ${ }^{52}$.

Esta segunda posición de supremacía de la ley por encima la Constitución fue la que, finalmente, acabó imponiéndose. Fijémonos que la amplia mayoría de las transformaciones del modelo económico-social producidas durante las últimas décadas a las que nos hemos referido antes, se producen por vía de Ley o Decretos-Leyes, algunas de ellas, de dudosa constitucionalidad.

Como señala M. Prieto, las causas que propiciaron la imposición de este modelo fueron: la centralización y concentración del poder político durante el período de la provisionalidad del Gobierno Revolucionario, el carácter constituyente del Consejo de Ministros, así como la infeliz decisión de la Sala de Garantías en 1952 de no admitir el recurso de inconstitucionalidad presentado contra los estatutos «mal llamados constitucionales» de Fulgencio Batista, lo que creó un rechazo mayor hacia la intervención del aparato judicial en la esfera política y, junto a ello, la necesidad de una administración fuerte, capaz de realizar las grandes transformaciones del país sin que sus decisiones y disposiciones fuesen frenadas por reclamacions individuales ${ }^{53}$.

51 Como otros ejemplos de la pervivencia del valor normativo imperativo de la preceptiva constitucional Prieto cita sentencias de la precitada sala cuando declaró que la violación de una norma constitucional por falta de aplicación de los preceptos legales pertinentes determina la inconstitucionalidad de la sentencia en sí misma (Vid. Boletín del Tribunal Supremo, Año 1, Núm. 10, octubre 1966, pp. 13-14, Sala de Garantías Constitucionales y Sociales, Recurso de inconstitucionalidad, Sentencia Núm. 10 de 26 de octubre 1966, juez ponente Dr. Fernando Álvarez Tabío). Igual criterio, afirma, se sostuvo cuando declaró que el recurso de inconstitucionalidad era la vía adecuada contra la sentencia en sí misma en los casos de aplicación directa de los preceptos de la ley fundamental, enfatizando a su vez que la declaración de inconstitucionalidad requería una contradicción flagrante entre la resolución combatida y un precepto constitucional (Vid. Boletín del Tribunal Supremo, Año iv, Núm. 3, mayo-junio de 1969, pp. 186-189, Sala de Garantías Constitucionales y Sociales, Recurso de inconstitucionalidad, Sentencia Núm. 7 de 3 de junio de 1969, juez ponente Dr. Fernando Álvarez Tabío). (M. PRIETO, «En pos de la aplicabilidad directa de la constitución cubana de 1976 (un breve comentario)», Op. cit. p. 197).

52 La ausencia de la norma de desarrollo del precepto constitucional impide la entrada en vigor del mismo, pronunciamiento en Sentencia 5 de 8 de junio de 1966, Boletín del Tribunal Supremo, Núm. 6, junio de 1966, pp. 8-9; Sentencia 9 de 29 de julio del propio año, Boletín del Tribunal Supremo, Núm. 7, julio de 1966, p. 12; y Sentencia 12 de 9 de diciembre de 1966, Boletín del Tribunal Supremo, Núm. 12 de diciembre de 1966, p. 17, en la que adujo no poder aplicar el artículo 105 de la Ley Fundamental por falta de ley de desarrollo. Sobre el mismo tema, la inamovilidad constitucional, pero en la jurisdicción contencioso-administrativa, vid. Boletín del Tribunal Supremo, Núm. 4, abril de 1996, Sent. 9 de 18 de abril de 1966, p. 9 (citado por M. PRIETO, Op. cit., p. 198).

53 Ibid. p. 198-199. 
La Constitución de 1976 acabó institucionalizando un diseño constitucional del poder que fundamentado en el principio de unidad de poderes, se caracterizó no por la subordinación del poder a la Constitución, sinó a la inversa, de la Constitución al poder ${ }^{54}$, bajo la máxima imperante en muchos países socialistas de que «no se hace la Revolución con el Derecho sino con la política», lo que hacía del texto constitucional más un programa que una norma vinculante de la actuación de los poderes públicos y de la ciudadania. ${ }^{55}$

Frente a ello, Prieto y Pérez llevan tiempo proponiendo recuperar la idea de supremacía de la Constitución, aplicabilidad directa de ésta y de un Tribunal Constitucional que garantice la subordinación a la misma del poder y del resto de normas infraconstitucionales. Su defensa del carácter normativo de la Constitución no equivale a una comprensión «legalista», que sólo priorice la norma sobre los fines políticos de la Revolución. En su lugar, proponen un modo concreto de relacionarlos: traducir los fines de la Revolución a derechos fundamentales. Puede considerarse el objetivo del Estado de cumplir «fines revolucionarios» en este sentido: realizar el catálogo de derechos fundamentales que establece $e^{56}$.

Sin embargo, a pesar de que la nueva Constitución reconoce ahora, formalmente, la supremacía constitucional en el art. 7 («La Constitución es la norma suprema del Estado. Todos están obligados a cumplirla»), en la práctica, continua sin reconocer la existencia de una sala constitucional del TS y mantiene el mismo modelo de control

${ }^{54}$ No existe en Cuba ni Tribunal Constitucional, ni sala constitucional del TS. Los órganos encargados de llevar a cabo el control de constitucionalidad, de acuerdo con la Constitución de 1976, eran la Asamblea Nacional, el Consejo de Estado y la Fiscalía General de la República. Por un lado, en su articulo 75 c), ch)1 la Constitución regulaba como atribución de la Asamblea Nacional del Poder Popular, la facultad de decidir la constitucionalidad de las leyes, decretos leyes y demás disposiciones generales, por lo tanto es facultad de este órgano legislativo la de salvaguardar la Constitución. La facultad de salvaguarda de la Constitución está en poder del único órgano con facultad constituyente y legislativa del país, del órgano que representa la soberanía popular, lo que doctrinalmente se justifica por el criterio de que quien mejor puede defender la Constitución es el pueblo y en su defecto, sus representantes. Por otro lado, el art. 90 ch), ñ), o) y p) 2 de la Constitución atribuían al Consejo de Estado, la interpretación general y obligatoria de las leyes vigentes, la suspensión de las disposiciones del Consejo de Ministro y los acuerdos y disposiciones de las Asambleas Locales del Poder Popular que no se ajusten a la constitución o a las leyes, revocar los acuerdos y disposiciones de las Administraciones Locales del Poder Popular que contravengan la Constitución, las leyes, los decretos leyes, los decretos y demás disposiciones dictadas por los órganos superiores , así como también aprobar sus reglamentos. A la vez, el art. 127 de la Constitución atribuía también a la Fiscalía General de la República, la defensa de la Constitución y la legalidad, como lo había hecho anteriorment el constitucionalismo soviético (Sobre los mecanismos de control de constitucionalidad existentes en Cuba, vid.: J. FERNÁNDEZ, «Los modelos de control constitucional y la perspectiva de Cuba hoy», M. PRIETO y L. PÉREZ (Comps.), Temas de derecho constitucional cubano, Félix Varela, La Habana, 2004; S.S. FERNÁNDEZ, «Cuba y el Control Constitucional en el Estado Socialista de Derecho: Reflexiones para su perfeccionamiento», en A. MATILLA (Comp.), Estudios cubanos sobre control de constitucionalidad (1901-2008), Porrúa, México D.F., 2009).

55 Sobre ello, vid. H. AZCUY, «Revolución y derechos», Cuadernos de Nuestra América, Vol. XII No. 23, La Habana, 1995, pp. 145-155.

${ }^{56}$ J.A. FERNÁNDEZ ESTRADA y J.C. GUANCHE, «Un socialismo de ley. En busca de un diálogo sobre el constitucionalismo socialista cubano en 2010», Caminos. Revista cubana de pensamiento socioteológico, Centro memorial Dr. Martin Luther King Jr., , Núm. 57, La Habana , 2010. 
de constitucionalidad existente en el anterior texto constitucional. Los arts. 108.e) f), 122.h) i) y 156 del texto reproducen el mismo modelo.

Aunque, como hemos señalado anteriormente, la ANPP, el Consejo de Estado y la Fiscalía General de la República ejercen control de constitucionalidad, en la práctica no existe un mecanismo de control eficaz que defienda el principio de supremacía constitucional con referencia al total de actos normativos y de actuaciones administrativas. Cuando el art. 108.e) de la Constitución señala que es función de la ANPP ejercer el control de constitucionalidad sobre las leyes, decretos-leyes, decretos presidenciales, decretos y demás disposiciones generales, ubica a este órgano como juez y parte del proceso legislativo, confundiendo en el mismo sujeto la función legislativa y la de control de constitucionalidad.

\section{III.III. La carta de derechos: luces y sombras}

El debate sobre la necesidad de adoptar una nueva carta de derechos llevaba también tiempo teniéndose en la isla. La Constitución nueva se queda muy por detrás de la regulación fuertemente garantista alcanzada, en las últimes décadas, por las constituciones del llamado nuevo constitucionalismo latinoamericano ${ }^{57}$. Básicamente, sus novedades es que incorpora explícitamente nuevos principios de aplicación e interpretación de derechos, redefine algunos derechos ya regulados y amplia nuevos derechos. En cuanto a las garantías, introduce una novedad importante que es el reconocimiento de una especie de recurso de amparo, a través del cual las personas pueden acceder a los tribunales, a través de un procedimiento preferente, expedito y concentrado, para solicitar la protección o restitución de derechos vulnerados.

La actual Constitución establece una nueva carta de derechos más larga que la anterior, estructurada y ordenada en seis capítulos (I. Disposiciones generales, II. Derechos, III. Las familias, IV. Deberes, V. Derechos y deberes de los extranjeros, y, VI. Garantías).

Si bien, la carta anterior tampoco establecía ningún tipo de jerarquización entre los derechos ${ }^{58}$, el nuevo texto explicita esta cuestión en el art. 41 que dice: «El Esta-

57 Sobre ello, vid. A. NOGUERA, Los derechos sociales en las nuevas Constituciones latinoamericanas, Tirant lo blanch, Valencia, 2010.

58 En la Constitución de 1976 no se utilizaba la categoría, común en las Constituciones, de «Derechos Fundamentales» de la que se deriva, implícitamente, una diferencia entre éstos y lo que no son considerados como tales. Además, la consagración positiva de un derecho como fundamental obliga a los operadores jurídicos a maximizar, en el momento de la interpretación constitucional, los mecanismos que permitan su protección frente a otros. La Constitución de 1976 no usa la expresión «derechos fundamentales», sino que habla de «derechos» sin más, eliminando cualquier tipo de jerarquía entre ellos (Sobre el debate acerca de la jerarquía entre derechos, vid. A. NOGUERA, ¿¿Derechos fundamentales, fundamentalísimos o, simplemente, derechos? El principio de indivisibilidad de los derechos en el viejo y en el nuevo constitucionalismo», Derechos y Libertades, Núm. 21, Instituto Bartolomé de las Casas, Universidad Carlos III, 2009). 
do cubano reconoce y garantiza a la persona el goce y el ejercicio irrenunciable, imprescriptible, indivisible, universal e interdependiente de los derechos humanos, en correspondencia con los principios de progresividad, igualdad y no discriminación». Con ello se incorporan en la Constitución los principios de indivisibilidad, interrelación e interdependencia de los derechos y el principio de progresividad.

Aunque no se incluye, explícitamente, el principio de prohibición de regresividad de los derechos, como sí hizo, por ejemplo, el art. 11.4 de la Constitución de Ecuador de 2008, al final del anteproyecto inicial sometido a la discuisón popular había un glosario donde se incorporaba este principio como parte de la definición del principio de progresividad reconocido en el actual art. 41.

No se incorporan, en cambio, de ninguna manera, ni la jerarquia constitucional de los tratados internacionales de derechos humanos firmados por el país, ni la cláusula abierta en el reconocimiento de derechos, ambos incluidos, por ejemplo, en los arts. 256.I y 13.II de la Constitución boliviana de 2009 o los arts. 23 y 22 de la venezolana de 1999.

La opción por la que se opta es otra. En el art. 39 del anteproyecto se hacía una formulación igual a la del art. 10.2 de la Constitución espanyola, señalándose que los derechos de la Constitución se interpretan de conformidad con los tratados Internacionales de derechos humanos ratificados por Cuba. Esta formulación no implica, como así lo ha señalado el Tribunal Constitucional espanyol en referencia al art. 10.2 del texto español de 1978, otorgar rango constitucional a los derechos proclamados en los instrumentos Internacionales de derechos humanos. ${ }^{59}$ La formulación que ha

59 El art. 10.2 de la Constitución espanyola estableció la misma formulación, cuando señala que los derechos constitucionales «se interpretarán de conformidad con la Declaración Universal de Derechos Humanos y los tratados y acuerdos internacionales sobre las mismas materias ratificados por España». $\mathrm{Al}$ interpretar este articulo, el TC ha dejado claro que con él no se otorga rango constitucional a los derechos y libertades proclamados en los Tratados Internacionales en cuanto no estén también recogidos en la Constitución. Así, La STC 36/1991, de 14 de febrero declaró que «esta norma se limita a establecer una conexión entre nuestro propio sistema de derechos fundamentales y libertades, de un lado, y los Convenios y Tratados internacionales sobre las mismas materias en los que sea parte España, de otro. No da rango constitucional a los derechos y libertades internacionalmente proclamados en cuanto no estén también consagrados por nuestra propia Constitución, pero obliga a interpretar los correspondientes preceptos de ésta de acuerdo con el contenido de dichos Tratados o Convenios, de modo que en la práctica este contenido se convierte en cierto modo en el contenido constitucionalmente declarado de los derechos y libertades que enuncia el capítulo segundo del título I de nuestra Constitución» (F.J.5). De este modo, en palabras del TC «aunque los textos y acuerdos internacionales del artículo 10.2 constituyen una fuente interpretativa que contribuye a la mejor identificación del contenido de los derechos cuya tutela se pide a este TC, la interpretación a que alude el citado artículo 10.2 del texto constitucional no los convierte en canon autónomo de validez de las normas y actos de los poderes públicos desde la perspectiva de los derechos fundamentales, es decir, no los convierte en canon autónomo de constitucionalidad». «Si así fuera, sobraría la proclamación constitucional de tales derechos, bastando con que el constituyente hubiera efectuado una remisión a las Declaraciones internacionales de Derechos Humanos o, en general, a los tratados que suscriba el Estado español sobre derechos fundamentales y libertades públicas». SSTC 64/1991, de 22 de marzo (F.J.4), 372/1993, de 13 de diciembre, (F.J.7), 41/2002, de 25 de febrero (F.J.2) y STC 236/2007 de 7 noviembre (F.J.5). 
quedado en la Constitución cubana en vigor elimina, incluso, esta concepción, limitándose, el art. 8, a otorgar primacía a la Constitución por encima de los tratados internacionales.

Tampoco se reconoce el principio de universalidad de los derechos fijado, por ejemplo, en la Constitución ecuatoriana de 2008 que en su art. 11 dice: «El ejercicio de los derechos se regirá por los siguientes principios: (...) 2. Todas las personas son iguales y gozaran de los mismos derechos, deberes y oportunidades». Cuando anuncia los derechos, el texto ecuatoriano habla de «las personas», sólo en el capítulo quinto del Título II (Derechos de participación) habla de «Las ecuatorianas y ecuatorianos», limitando los derechos políticos a los nacionales, pero no el resto. El texto cubano, por el contrario, en su art. 91.e) establece que solo los extranjeros con residencia legal se equiparan a los cubanos en el disfrute de los derechos, aunque no necesariamente en condiciones de plena igualdad, puesto que deja abierta la posibilidad que la ley pueda otorgar un trato desigual en el acceso a los mismos entre cubanos y extranjeros residentes.

Asimismo, otra novedad a destacar de la Constitución es que reformula varios derechos ya reconocidos y amplía el listado.

Uno de estos derechos que se reformulan es, por ejemplo, el de reunión, asociación y manifestación. El nuevo art. 56 introduce una destacada modificación respecto a su homólogo en la Constitución anterior, el art. 54. El cambio que introduce el art. 56, es que ahora el derecho de asociación, reunión y manifestación no aparece vinculado a las «organizaciones de masas» como sí se hacía en el art. 54 del texto de 1976. A ellas se dedica otro artículo, el 14, según el cual «el Estado reconoce y estimula» a las organizaciones de masas, las cuales «agrupan en su seno a distintos sectores de la población, representan sus intereses específicos y las incorporan a las tareas de la edificación, consolidación y defensa de la sociedad socialista». Pero, al margen de este reconocimiento, el art 56, por el contrario, habla del derecho en términos generales sin someterlo a ninguna condición, excepto, únicamente y como en casi todas las Constituciones, al respeto del orden público y la ley.

En materia de derechos económicos y sociales a la educación y la salud, cuya garantía en los momentos económicos más difíciles habían sido el principal emblema de legitimación del sistema a nivel nacional e internacional, observamos pocos cambios.

En la educación, mientras que la Constitución anterior establecía la gratuidad en todos sus niveles, sin excepción, el art. 84 del anteproyecto de Constitución presentado en julio del 2018 fijaba la gratuidad «desde el preescolar hasta la enseñanza universitaria de pregrado», mientras que «la formación posgraduada y la educación de las personas adultas» se garantizaba «de conformidad con las regulaciones establecidas», y abría la posibilidad de suprimir su gratuidad e incluso establecía como objetivo el potenciar la entrada del capital privado extranjero en la financiación de la investigación científica.

No obstante, la posibilidad de eliminación de la gratuidad de ciertas etapas de la educación fue una de las cuestiones impugnadas por la ciudadanía durante la fase de 
consulta ciudadana y, por lo tanto, eliminada del proyecto final de Constitución aprobado en referéndum que, del mismo modo que la Constitución anterior, mantiene la gratuidad de la educación «desde la primera infancia hasta la enseñanza universitaria de posgrado» (Art. 73).

En cuanto a la sanidad, el Estado continúa garantizando el acceso y la gratuidad de los servicios de salud, pero ahora añade que «la ley define la manera en que los Servicios de salud se prestan» (Art. 72), y se abre aquí la posibilidad que no sean prestados directamente por el Estado.

El contenido del derecho de igualdad adquiere un mayor desarrollo de sus supuestos, incluyendo nuevas menciones explícitas a la prohibición de discriminación por género, identidad de género, orientación sexual, origen étnico y discapacidad (Art. 42). Aunque, seguramente, la novedad más problemática en este sentido fue el reconocimiento, en el art. 68 del anteproyecto presentado, del matrimonio «entre dos personas». Este aspecto fue impugnado por la ciudadanía en la fase de consulta ciudadana. Ante esto, la Asamblea Nacional optó para retirar este artículo del texto final y añadir una disposición transitoria, la decimoprimera, que establece: "Atendiendo los resultados de la Consulta Popular realizada, la ANPP, en el plazo de dos años de vigencia de la Constitución, iniciará el proceso de consulta popular y referéndum del proyecto de Código de Familia, en el cual tiene que figurar la forma de constituir el matrimonio».

Respecto a la ciudadanía, se pasa de la prohibición de la doble ciudadanía a un nuevo redactado, en el art. 36, donde se establece simplemente que, en territorio nacional, los ciudadanos cubanos se rigen por esa condición y no pueden hacer uso de una ciudadanía extranjera, pero sin impedir la posibilidad de tenerla sin perder la cubana como sucedía anteriormente.

En cuanto a las garantías, a lo largo de las últimas dos décadas, las constituciones del nuevo constitucionalismo latinoamericano han introducido nuevos instrumentos jurisdiccionales populares para la defensa de derechos. En concreto, introdujeron novedades en materia de los sujetos con legitimidad activa para exigir jurisdiccionalmente los derechos (reconocimiento de sujetos colectivos informales o circunstanciales como plataformas, asambleas, etc.), de democratización de acciones jurisdiccionales ya existentes (reconocimiento de los ciudadanos de poder presentar acciones ciudadanas de inconstitucionalidad por acción o por omisión) y de introducción de nuevas acciones jurisdiccionales (por ejemplo, las llamadas acciones populares mediante las que un grupo de personas afectadas por una misma causa y que requieren de un remedio colectivo puede defender sus derechos o intereses colectivos sin necesidad de abogados y obteniendo una resolución rápida). Ninguna de estas novedades es incorporada en la Constitución cubana. La principal novedad es que se introduce el reconocimiento, en el art. 99, de un recurso preferente, expedito y concentrado para la protección de los derechos. Sin embargo, si algo caracteriza el nuevo constitucionalismo latinoamericano es la misma protección de todos los derechos sin distinción entre ellos. El último párrafo del citado art. 99 
referido al recurso preferente y concentrado, dice que la ley establece aquellos derechos amparados por esta garantía, pudiendo, mediante leyes en el futuro, excluir determinados derechos de este recurso preferente y sumario y, por tanto, fijando derechos de primera y de segunda.

Por otra parte, es verdad y también como sucedía con la Constitución anterior, que el texto constitucional no sólo proclama derechos y establece los mecanismos procesales para su protección, sino que además establece, a lo largo de su redactado, distintas garantías normativas, esto es, directrices básicas de las políticas públicas que debe desarrollar el Estado. Así, por ejemplo, en el art. 77 se dice que el Estado deberá «brindar especial protección a aquellos adolescentes graduados de la enseñanza técnica y profesional u otros que, en circunstancias excepcionales definidas en la ley, son autorizados a incorporarse al trabajo, con el fin de garantizar su adiestramiento y desarrollo integral». Sin embargo, el problema está en que estas garantías normativas quedan reducidas a meros principios rectores no vinculantes de las políticas públicas en tanto que, como hemos señalado anteriormente, no existe una sala constitucional del Tribunal Supremo ante quien exigirlas.

En resumen, podemos decir que la carta de derechos de la Constitución cubana no logra ponerse al nivel del carácter fuertemente garantista de constituciones recientes como la de Venezuela de 1999, Ecuador de 2008 o Bolivia de 2009.

\section{III.IV. El Partido, la organización politica y la participación ciudadana}

El sistema institucional diseñado por la Constitución de 1976 introdujo elementos participativos como la consulta popular (art. 75.b), el referendo (art. 75.u.) o la iniciativa legislativa popular (art. 88.g) y de mandato imperativo tales como la nominación directa de candidatos por el pueblo y su posterior elección directa en asambleas municipales, revocación de delegados y diputados, o régimen participativo a nivel local con rendición de cuentas a los electores.

Estos mecanismos funcionaron durante años ${ }^{60}$, sin embargo, junto a ellos la Constitución, dictada en el apogeo de la era en que Cuba reconstruía el perfil de democracia socialista bajo la influencia de la URSS, contenía también el germen para el desarrollo de un proceso de centralización y burocratización del espacio de toma de decisiones políticas ${ }^{61}$.

${ }^{60}$ Sobre las cifras de participación popular en las instituciones de rendición de cuentas, nominación de candidatos, revocación de mandato, etc. en la isla, vid. J. LEZCANO, El sistema político cubano, Fondos del Centro de Investigaciones Psicológicas y Sociológicas (CIPS), La Habana, 1999, pp. 22-23.

61 Para una crítica de los espacios de participación ciutadana en Cuba, vid. O. D’ANGELO HERNÁNDEZ, «Participación y construcción de subjetividad social para una proyección emancipatoria», D. CRISTOBAL ALLENDE y M.I. DOMINGUEZ, «La participación social desde la perspectiva de la juventud cubana», ambos en C. LINARES, P.E. MORAS y Y. RIVERO, La participación. Diálogo $y$ debate en el contexto cubano, Centro de Investigación y Desarrollo de la Cultura Cubana Juan Marinello, La Habana, 2004. 
Con la constitucionalización en 1976 de la Unidad de Poder y el centralismo democrático como principios de organización funcional del Estado (Art. 68) o el reconocimiento explícito del PCC como fuerza dirigente superior de la sociedad y el Estado (Art. 5), el texto anterior consagraba la idea soviética de que si la Revolución resulta el orden estatuido por la voluntad del pueblo, entonces la Revolución ha venido a realizar un orden cósmico que la significa, per se, como el criterio del bien: la medida de todas las cosas. En consecuencia, esta cualidad queda trasvasada al Estado. Así la Revolución se convierte en «Estado Revolucionario», encarnado en las políticas concretas dictadas por el Estado, y, por tanto, es insostenible, desde el punto de vista teórico, una impugnación a ese presupuesto fundacional ${ }^{62}$.

Ello ha dado lugar a una burocracia socialista que pasa a suplantar el lugar de sus representados, que recibe el mandato imperativo de un partido burocrático que sustituye la elaboración política ciudadana, para poder actuar sin control social, eludiendo las formas institucionales de control de la representación ${ }^{63}$.

El diseño institucional creado en la nueva Constitución no rompe con el modelo centralizado y burocratizado de ejercicio del poder, sinó que lo reproduce. El actual art. 101 reproduce los mismos principios de organización y funcionamiento de los órganos del Estado que el anterior art. 68.

El art. 102 de la Constitución establece que la ANPP es el órgano supremo del poder del Estado, no obstante, se limita la actividad de ésta a dos períodos ordinarios de sesiones al año (Art. 110.b). Esto significa que se reune dos veces al año al finalizar cada semestre por un término de dos o tres días cada período. Aunque existen comisiones permanentes de trabajo, el resto de días del año, los diputados mantienen su vínculo laboral con su centro de trabajo del que obtienen su medio de vida. No obtienen remuneración por ser diputados (Art. 115). Ello hace que, en la práctica, sea el Consejo de Estado y sus cargos dirigentes (el Presidente y Vicepresidentes), junto a la ahora nueva figura del Primer Ministro ${ }^{64}$, quienes tomen las decisiones políticas fundamentales del día a día. Como señala Julio César Guanche, «a falta de ejercicio

${ }^{62}$ J.A. FERNÁNDEZ ESTRADA y J.C. GUANCHE, «Se acata però (...) se cumple. Constitución, república y socialismo en Cuba», The Latin Americanist, Vol. 53, núm. 3, 2009, pp. 33-54.

${ }_{63}$ Los pronunciamientos expresados por Fidel Castro al lanzar el «Proceso de rectificación de errores y tendencias negatives» (1986) y los recogidos durante la discusión del Llamamiento al IV Congreso del PCC (1990-1991) dan cuenta del nivel de insatisfacción con la eficacia democrática del sistema a nivel de la población, pero también de la dirigencia revolucionaria (compensada con el nivel de bienestar material más alto experimentado en la historia de la Revolución (1973-1985), resultado de la alianza con la URSS) (Vid. J. VALDÉS PAZ, «La transición socialista en Cuba: continuidad y cambio en los 90», en J. VALDÉS PAZ, M. ESPINA y otros, La transición socialista en Cuba. Estudio sociopolítico, Ciencias Sociales, La Habana, 1994, pp. 33-72).

${ }^{64}$ Con la creación de la figura del Primer Ministro, la isla vuelve, como sucedía en el país antes de la Constitución de 1976, a diferenciar entre Jefe de Gobierno y jefe de Estado. El Primer Ministro es designado por la Asamblea Nacional del Poder Popular, a propuesta del Presidente de la República y a quien rinde cuentas, por un período de cinco años. Éste ejercerá como administrador general ejecutivo del Estado-Gobierno, auxiliado por el Consejo de Ministros. Su creación constituye una innovación de carácter burocrático que no afecta al carácter concentrado y vertical del poder. 
permanente y profesional de sus diputados, la ANPP no tienen más remedio que suplir su ausencia de dominio, información y competencias con la ratificación generalmente unánime, de las disposiciones generales de gobierno concentradas en el Consejo de Estado» ${ }^{65}$. Si a ello le añadimos que existe una coincidencia entre los cargos dirigentes del Consejo de Estado con los del Comité Central del Partido, se acaba reproduciendo el modelo de centralización vertical de las funciones de gobierno en el aparato burocrático.

Aunque el nuevo texto establece como novedad, en el art. 126, una limitación de mandato al Presidente del Consejo de Estado por un período de cinco años, reelegible solo una vez, ello no evita la reproducción del sistema concentrado de Poder. Además, tampoco se prohíbe la posibilidad de rotar de cargo dentro de la estructura del Consejo de Estado u otros órganos con funciones de poder.

\section{III.V. La administración territorial del Estado: la limitada autonomía municipal y creación del gobernador provincial}

El fuerte centralismo vertical en materia política que acabamos de describir queda fortalecido a través de la propia organización administrativo-territorial del Estado.

Una de las propuestas que, desde diferentes sectores académicos, se han hecho durante años para profundizar la democratización del sistema, ha sido la de descentralización de mayores competencias en los municipios y la plena garantía de la autonomia local, en tanto que éste conforma el eslabón político-administrativo más próximo a los ciudadanos, donde la participación se da de manera más real y verdadera y donde es posible, en mayor grado, el debate, control y agregación de demandas populares a la agenda política ${ }^{66}$. Sin embargo, la Constitución tampoco establece avances en esta dirección.

Algunas propuestas concretas, han sido la necesidad de concreción y regulación constitucional de las competencias de los órganos locales en lo relativo a la toma de decisiones ${ }^{67}$. La Constitución anterior, en el art. 106.e), establecía que corresponde a las asambleas municipales adoptar acuerdos y dictar disposiciones sobre «asuntos de interés local», sin establecer una definición de este término. Tampoco existe una definición de los asuntos sobre los que compete tomar decisiones a los Consejos Popu-

65 J.C. GUANCHE, «Parlamento cubano: algunos problemas frente a 2018 (I parte)», Revista Sin Permiso (edición virtual), 18 de abril de 2018.

66 Estas propuestas pueden encontrarse en: L. PÉREZ y M. PRIETO, «Ejercer gobierno: una capacidad potencial de las asambleas municipales del poder popular», en M. PRIETO y L. PÉREZ (comp.), Temas de derecho constitucional cubano, Op. cit. p. 204; M.A. DEL RIO, La participación popular en el proceso de toma de decisiones públicas en el ámbito local comunitario en Cuba. Su régimen jurídico, Tesis de opción al grado de doctora en ciencias jurídicas, Universidad Central «Marta Abreu» de las Villas, Santa Clara, 2002.

${ }^{67}$ M.A. DEL RIO, La participación popular en el proceso de toma de decisiones públicas en el ámbito local comunitario en Cuba. Su régimen jurídico, Op. cit. pp. 22-23. 
lares a tenor de la Ley 91 de 13 de julio de 2000, lo cual provoca muchas veces confusión en la interpretación del alcance de sus facultades decisorias. La actual Constitución continúa sin especificar tales atribuciones. Su art. 191.g) sigue estableciendo que corresponde a la Asamblea Municipal del Poder Popular adoptar acuerdos y dictar disposiciones sobre «asuntos de interés municipal» sin desarrollar cuales son. Tampoco en los artículos referidos a los Consejos populares (arts. 198 y 199) se especifican las atribuciones a éstos.

Además, el pleno ejercicio de la autonomía municipal exigiría, al contrario de lo que sucede actualmente, que las decisiones de los entes locales no estuvieran subordinadas a la aprobación de órganos superiores y que dispusieran de capacidad para determinar su propio presupuesto. Tampoco ninguna de estas dos cuestiones es reconocida por la Constitución.

El art. 184 j) y k) constitucionaliza claramente la subordinación de los órganos municipales a las instancias provinciales cuando señala como atribución de la nueva figura del Consejo Provincial que, presidido por la también nueva figura del Gobernador provincial, pasaría a sustituir a las Asambleas Provinciales del Poder Popular $(\mathrm{APPP})^{68}$, proponer al Consejo de Estado o a la ANPP la suspensión de los acuerdos

${ }^{68}$ La nueva Constitución elimina las Asambleas Provinciales del Poder Popular y crea en su lugar a un Gobierno Provincial integrado por el Gobernador Provincial, designado a propuesta del Presidente de la República, por la Asamblea Nacional del Poder Popular, o en su caso por el Consejo de Estado, por el término de cinco años (art. 170) y por un Consejo Provincial, presidido por el Gobernador e integrado por derecho propio, por el Vicegobernador Provincial, los presidentes de las asambleas locales del Poder Popular correspondientes, los intendentes municipales y demás miembros que determine la ley (art. 177). Este proceso de eliminación de las APPP es la culminación de un proceso de transformación de éste órgano que venía produciéndose desde hace algunos años. Desde la constitución de los órganos del poder popular se afirmaba que las Asambleas son los máximos órganos locales del poder estatal, pero la práctica fue conduciendo cada vez más a que el ejercicio real de ese poder no residiera en la Asamblea, sino en el órgano concebido para representarla entre períodos de sesiones y exclusivamente como ejecutante de sus decisiones: los Comités Ejecutivos al nivel correspondiente. Esta realidad era señalada críticamente en la práctica cotidiana y fue planteada en diferentes estudios hechos sobre el funcionamiento del sistema estatal. Unido a ello, los Comités Ejecutivos también presentaban insuficiencias técnicas en su trabajo, condicionadas entre otras cosas por el hecho de que sólo delegados electos podían formar parte de él, lo que hacía mayor la insatisfacción con su gestión. En respuesta a esta situación se decidió la eliminación de los Comités Ejecutivos. Paralelamente, la Constitución estableció que, en adelante se crearán las Administraciones Locales cuyos componentes no tienen que ser necesariamente delegados electos. En enero de 1993 se emite el Acuerdo 2654 del Comité ejecutivo del Consejo de Ministros, el cual contiene las Normas referentes a la organización, integración y atribuciones de las administraciones municipales y provinciales subordinadas a las Asambleas del Poder Popular (posteriormente, en el 2001, por Acuerdo No. 4047 del Comité Ejecutivo del Consejo de Ministros se aprueba el Reglamento de las Administraciones Locales y provinciales del Poder Popular), y desde 1995 circulan los Reglamentos de las Asambleas Municipales y Provinciales del Poder Popular, aprobados por acuerdo del Consejo de Estado de 13 de septiembre (Vid. J.P. GARCÍA BRIGOS, «La participación popular en la forma de organización del Estado socialista cubano», en A. VAZQUEZ y R. DÁVALOS (comp.), La participación social. Desarrollo urbano y comunitario, I Taller de Desarrollo Urbano y Participación, Ed. Facultad de Filosofía e Historia/Departamento de Sociología, Universidad de La Habana, 1996, p. 40-41).

N.o 105, mayo-agosto 2019, págs 361-396 
o disposiciones de las Asambleas Municipales de su demarcación, cuando contravengan las normas legales superiores o afecten los intereses de la comunidad. En el mismo sentido el art. 179.i) otorga al Gobernador provincial la facultad de suspender los acuerdos y disposiciones de los consejos de la administración municipal. Con ello, se otorga la facultad al Gobierno provincial presidido por un gobernador designado a propuesta del Presidente de la República, de suspender las decisiones de las asambleas municipales o consejos de administración municipal si considera que afectan a los intereses de la comunidad.

Otro de los elementos que garantizan la autonomía municipal y hacen de los municipios instancias reales de poder y participación es la posibilidad de determinar, autónomamente, su propio presupuesto. En la actualidad, quien determina la distribución económica por esferas es la Dirección Provincial de Finanzas, al municipio sólo le queda administrar. El art. 7.n) del Reglamento de las Asambleas Municipales del Poder Popular dice que éstas deben «aprobar el plan económico-social y el presupuesto del municipio, ajustándose a las políticas trazadas para ello por los organismos competentes de la Administración Central del Estado, y controlar su ejecución» ${ }^{69}$.

La Constitución no contradice este modelo. En su art. 191.b) dice que es función de las AMPP «aprobar y controlar, en lo que le corresponda, el plan de la economía, el presupuesto y el plan de desarrollo integral del municipio», manteniendo la subordinación, en el diseño presupuestario, de la administración local a las instancias superiores.

En resumen, en lugar de crear un nuevo modelo administrativo territorial y de competencias que permitiera, siguiendo las bases de la democracia socialista, la puesta en marcha de procesos participativos de toma de decisiones de abajo hacia arriba, la nueva Constitución establece un diseño que reproduce un modelo vertical de arriba hacia abajo donde las instancias centrales del Estado centralizan todo el Poder.

\section{III.VI. La propiedad y el modelo económico}

El art. 18 de la Constitución abre el Título II (Fundamentos económicos) y señala que la forma principal de propiedad en el país es la «propiedad socialista de todo el pueblo sobre los medios fundamentales de producción». Esto se complementa con

${ }^{69}$ Para elaborar su propuesta de presupuesto anual, hoy en día, el órgano municipal se atiene a las directivas provinciales. Una vez elaborado el proyecto de presupuesto lo presenta a la Dirección provincial de Finanzas, quien lo evalúa y presenta su versión a la Asamblea Provincial y al Ministerio de Finanzas y Precios. Este último, haciendo un desglose por provincias, lo somete en forma global a la aprobación de la Asamblea Nacional. Una vez aprobado, retorna al municipio a través de la Dirección Provincial de Finanzas, la que ya ha determinado definitivamente su distribución por esferas. Si bien es cierto que las Asambleas municipales elaboran el proyecto, cuando lo reciben para su aprobación final tal acto se convierte en una formalidad pues el documento, aun cuando puede haber variado en el proceso anterior, ya ha sido aprobado por todas las instancias superiores. 
el art. 27 que afirma que «la empresa estatal socialista es el sujeto principal de la economía nacional».

Sin embargo, la necesidad de adelgazamiento del ineficaz sector estatal obliga a desarrollar otros tipos de propiedad y/o gestión de los medios de producción y servicios.

En esta línea, el art. 22 reconoce estos tipos de propiedad: la socialista de todo el pueblo; la cooperativa; la mixta; de las organizaciones políticas, de masas y sociales; la privada, y la personal. Dentro de esta enumeración hay dos novedades respecto la Constitución anterior: la primera es que se reconoce la propiedad cooperativa, en general. Las pocas referencias que la Constitución de 1976 hacía a la propiedad cooperativa hacían referencia únicamente a las cooperativas agropecuarias. La segunda es la referencia a la propiedad privada. La Constitución anterior reconocía únicamente la personal. Ambas aparecen como nuevas formas de propiedad emergentes. En función de por cual de estos dos modelos se acabe optando, el modelo económico de la isla será uno u otro. Detengámonos respecto a cada uno de estos dos modelos: el privado y el cooperativo.

Por un lado, en cuanto al sector privado, el proyecto reconoce ahora el papel del mercado $^{70}$ en la economía, abre la posibilidad para la privatización de la propiedad y/o gestión de un amplio número de bienes y servicios y reduce la participación de los trabajadores en las ramas de la economia.

La Constitución anterior, en su art. 15, listaba el conjunto de los bienes que conformaban la propiedad social y afirmaba que eran inalienables ${ }^{71}$, salvo casos excepcionales, donde debían cumplirse dos requisitos: que dicha transmisión se destine a los fines de desarrollo del país, y que no afecte los fundamentos del Estado, es decir, la «existencia de una economía basada en la propiedad socialista de todo el pueblo».

La nueva Constitución introduce cambios importantes en este artículo, que ahora pasa a ser el art. 23. En concreto, elimina del listado de bienes inalienables, imprescriptibles e inembargables: los centrales azucareros, las fábricas, los medios fundamentales de transporte, empresas, bancos, instalaciones y bienes nacionalizados y expropiados, así como granjas del pueblo, fábricas e instalaciones económicas, sociales, culturales y deportivas construidas. Asimismo, éstos quedan también fuera de los dos requisitos consignados para la transmisión de derechos, es decir, se puede auto-

${ }^{70}$ El art. 18 de la Constitución incluye la regulación del mercado dentro del marco de la planificación económica.

71 Estos bienes listados en la Constitución son: «las tierras que no pertenecen a los agricultores pequeños o a cooperativas integradas por los mismos; sobre el subsuelo, las minas, los recursos maritimos naturales y vivos dentro de la zona de su soberania, los bosques, las aguas, las vias de comunicación; sobre los centrales azucareros, las fábricas, los medios fundamentales de transporte, y cuantas empresas, bancos, instalaciones y bienes han sido nacionalizados y expropiados a los imperialistas, latifundistas y burgueses, así como sobre las granjas del pueblo, fábricas e instalaciones económicas, sociales, culturales y deportivas constru idas, fomentadas o adquiridas por el Estado y las que en el futuro contruya, fomente o adquiera» (art. 15). 
rizar que otros actores los usen, disfruten y gestionen aunque ello afecte los fundamentos del Estado, y aunque no contribuya al desarrollo del país ${ }^{72}$.

Respecto a los otros bienes ubicados dentro de la propiedad socialista de todo el pueblo (las infraestructuras de interés general, principales industrias e instalaciones económicas y sociales, así como otras de carácter estratégico), que siguen como inalienables excepto en los casos excepcionales expuestos, el último párrafo del art. 24 añade que la transmisión de otros derechos sobre estos, así como su gestión, se establecerá a través de la ley, cosa que puede abrir la puerta a la gestión privada de la propiedad estatal. Además, en cuanto a la concentración de propiedad, el art. 22 del anteproyecto decía: «El Estado regula que no exista concentración de la propiedad en personas naturales o jurídicas no estatales». Este artículo se ha modificado en la versión definitiva de la Constitución. El actual art. 30 dice: «La concentración de la propiedad en personas naturales o jurídicas no estatales es regulada por el Estado», eliminándose el fragmento «que no exista». En ninguno de los dos textos, no obstante, no se dice nada sobre la concentración de la gestión de bienes y servicios de propiedad estatal en una misma empresa, cosa que no deja de ser otra forma de concentración.

Especialmente, desde 2010 en adelante, el auge del sector privado en Cuba se ha producido de la mano de la antes citada flexibilización del trabajo por cuenta propia. El conjunto de medidas señaladas que se adoptan ese año, implica un cambio importante respecto la existencia de este sector, el cual, si bien antes era visto con recelo aunque se lo aceptaba como irremediable y necesario ante la situación económica, ahora pasa a verse como plenamente compatible con la esfera pública, dentro de los contornos de la transición socialista. Cuando se aprobó la ampliación y flexibilización del trabajo por cuenta propia, en septiembre-octubre del año 2010, ejercían esta modalidad unas 157 mil personas. En agosto del año 2011 ya eran 333.206. En mayo de 2017, ya eran 556.064 las personas inscritas en esa forma de empleo (un $12 \%$ del total de ocupados del país), y las cifras continúan en ascenso ${ }^{73}$.

Por otro lado, la nueva Constitución introduce novedades en el ámbito del sector cooperativo. Hasta 2012, solo se reconocían en Cuba cooperativas de tipo agropecuario (Cooperativas de Créditos y Servicios, Cooperativas de Producción Agropecuaria y Unidades Básicas de Producción Cooperativas). La cooperativa se entendía además, como una forma de organizar un patrimonio del Estado cedido en usufructo a la cooperativa o a sus socios y cuyas decisiones estaban supeditadas al ministerio del que dependieran. A partir de 2012 y siguiendo los lineamientos aprobados por el VI Congreso del PCC de 2011, el Decreto ley 305/2012 del Consejo de Estado «De las cooperativas no agropecuarias» y el Decreto ley 306/2012 del Consejo de Estado «Del régimen especial de seguridad social de los socios de las cooperativas no agropecuarias» abren la posibilidad para la constitución de cooperatives no agropecuarias en la

72 Sobre ello, vid. L.E. AYBAR TOLEDO, «El proyecto de Constitución abre puertas a la privatización de la propiedad social», La Tizza Cuba, 10 de septiembre de 2018.

73 A. GARCÍA ELIZALDE, «El sindicato, apoyo para el trabajador cuentapropista», Periódico Granma, La Habana, 23 de mayo de 2017. 
isla ${ }^{74}$. Ahora la cooperativa pasa a entenderse como una persona jurídica de derecho privado sin relación con los organismos de Estado y que puede fijar libremente los precios de sus productos (art. 25 DL 306 y 66.2 D 309). Asimismo, reconoce también las llamadas cooperativas de segundo grado como forma de federación de distintas cooperativas para organizar actividades complementarias entre ellas ${ }^{75}$.

Estas cooperativas son incluídas en el art. 22 de la Constitución que reconoce la propiedad cooperativa, en general, en igualdad de condiciones que la estatal, la mixta, la de las organizaciones sociales y de masas y la personal. El art. 21 del anteproyecto nombraba las diferentes formas de propiedad citadas y, seguidamente, incluía un último párrafo del artículo donde se señalaba que el Estado «estimula aquellas formas de propiedad de carácter más social», por lo que se entendía que se fomentaría la propiedad cooperativa frente a la privada. En el texto constitucional aprobado definitivamente, esta última frase ha sido eliminada del actual art. 22 y sustituida por «todas las formas de propiedad sobre los medios de producción interactúan en condiciones similares».

Con el fin de fomentar las cooperativas, el Estado ha adoptado medidas como las de permitirles no pagar alquiler durante el plazo de un año si reparan instalaciones arrendadas al Estado o cedidas en usufructo con la finalidad de gestionar esa propiedad estatal bajo la forma cooperativa (art. 51 D. 309). También se les otorga toda una serie de beneficios fiscales especialmente cuando se trata de venta de productos agropecuarios (Resolución Ministerio de Finanzas y Precios 427/2012).

Sin embargo, quedan todavía muchas deficiencias a superar si lo que se quiere es facilitar este tipo de cooperativas. Deficiencias como un proceso legal de constitución demasiado largo, complicado, burocratizado y supeditado a la voluntad administrativa. Un régimen económico confuso. $\mathrm{O}$, un régimen de disciplina social y solución de conflictos poco eficaz ${ }^{76}$.

Son varios los autores cubanos que llevan años afirmando que el vaciamiento del sector estatal no en favor del sector privado sino del cooperativo permitiría amortiguar

${ }^{74}$ Cuanto a estas normas y en relación con ellas se dicta también el Decreto ley 309/2012 del Consejo de Ministros «Reglamento de las cooperativas no agropecuarias de primer grado», la Resolución 570/2012 del Ministerio de Economía y Planificación y la Resolución 427/2012 del Ministerio de Finanzas y Precios. A raíz de la aprobación de esta legislación, a primeros de julio 2013 ya habían comenzado a funcionar las primeras 124 cooperativas asociadas a actividades del transporte, la construcción, la recogida de materias primas y los mercados agropecuarios. Entre estas cooperativas la mayoría se desprenden del sector estatal (112) por no resultar esa forma de gestión eficiente, y el resto, surgen del trabajo por cuenta propia, además de éstas, un nuevo grupo de setenta y una ya ha sido aprobado y van a empezar a funcionar (A.M. PUYO, «la nueva normativa cubana de cooperativas no agropecuarias», Revista Vasca de Economía Social, Núm. 11, 2014, p. 179).

75 M.E. SILVEIRA PÉREZ, «Las cooperativas a la luz de los nuevos cambios económicos en Cuba. Actualidad y perspectivas de futuro», Cubalex, Revista electrónica de estudios jurídicos, Unión Nacional de Juristas de Cuba, octubre-diciembre de 2010.

76 Vid. A.M. PUYO, «la nueva normativa cubana de cooperativas no agropecuarias», Op. cit. pp. 183-198. 
los efectos negativos de este proceso y garantizar mayores niveles de redistribución de la riqueza y justicia social ${ }^{77}$. El desarrollo legislativo y la posibilidad de que el sector cooperativo pueda conformarse en una auténtica alternativa al Estado, siendo prioritario sobre el sector privado dependerá, en gran medida, de la regulación que se establezca en una futura Ley General de Cooperativas.

En resumen, la necesidad de adelgazamiento del ineficaç sector estatal obliga a desarrollar otros tipos de propiedad y/o gestión. La Constitución reconoce tanto la propiedad privada como la cooperativa y, a pesar de implementar medidas para favorecer estas últimas, la expansión del sector privado es cada vez mayor. En función de cual de estos dos modelos se acabe imponiendo, el modelo económico de la isla será uno u otro.

\section{CONCLUSIONES}

Tal como hemos expuesto en el texto, la Constitución de 2019 es la concreción jurídico-formal de un proceso constituyente material que viene refundando las relaciones económicas y sociales de la isla desde inicios de la década de los 90, con la caída del campo socialista y el inicio del denominado Período Especial. Este conjunto de transformaciones pueden dividirse en dos fases: el Período Especial y la reforma constitucional de 1992, y las transformaciones de la última década (2006-2018) que empiezan con el cambio en la dirección política del país de Fidel a Raúl Castro Ruz.

Fruto de todas estas transformaciones, el pasado mes de febrero de 2019 se aprobó la nueva Constitución cubana.

77 Camila Piñeiro Harnecker y Jesús Cruz Reyes llevan tiempo planteando la necesidad de que el vaciamiento del sector estatal se haga en favor, principalmente, del sector cooperativista, no de la empresa privada. Como dice Piñerio, ello permitiría aumentar la productividad del sector no estatal y la calidad de sus productos, sin que aumente la concentración de los medios de producción y garantizando la equidad en los ingresos. A la vez, facilitaría la cohesión social mediante la coordinación entre los intereses de las empresas no estatales y los intereses sociales de las comunidades, representados en gobiernos municipales, consejos populares u otras organizaciones sociales, y su control mediante vías directas (participación en cooperativas «múltiples») y, en la mayoría de los casos, mediante vías indirectas (regulaciones, contratos) más fáciles de fiscalizar dada su obligatoria e inevitable transparencia. La expansión de cooperativas también impulsaría a las empresas privadas a mejorar los salarios y condiciones de trabajo de los trabajadores contratados, pues crearía alternativas de empleo más digno y justo. Además, si se establecen mecanismos y espacios de coordinación con gobiernos locales, podrían disminuir los precios de los bienes y servicios que se ofertan en el sector no estatal (C. PIÑEIRO, « $i$ Y las cooperativas, cuándo? Potencialidades de las cooperativas para la actualización del modelo económico cubano», Palabra Nueva, núm. 211, 2011, pp. 55-56; J. CRUZ Y C. PIÑEIRO, «Una introducción a las cooperativas», en C. PIÑEIRO (comp.), Cooperativas y Socialismo: Una mirada desde Cuba, Editorial Caminos, La Habana, 2011, pp. 31-54; C. PIÑEIRO, «Ahora que sí van las cooperativas, vamos a hacerlo bien. Roles de las cooperativas en el nuevo modelo económico cubano», Revista Caminos, La Habana, 5 de febrero de 2013; Vid. También. R. MUÑOZ, G. DONÉSTEVEZ y J. GARCÍA, Desarrollo y cooperativismo: desafíos al modelo cubano de transición al socialismo, Editorial Caminos, La Habana, 2014). 
Si bien en materia de derechos, el texto constitucional incorpora nuevos principios de aplicación e interpretación de los derechos y amplía el listado de derechos reconocido, se queda atrás en muchos aspectos sin lograr alcanzar el carácter fuertemente garantista de las constituciones del llamado nuevo constitucionalismo latinoamericano aprobadas, durante las últimas décadas, por países latinoamericanos ubicados en la órbita ideológica de Cuba (Venezuela, Ecuador y Bolivia).

En cuanto a la reestructuración del sector económico, la necesidad de adelgazamiento del sector estatal obliga a desarrollar otros tipos de propiedad y/o gestión de los medios de producción y servicios. La Constitución abre la puerta a que ello se pueda hacer a través de nuevas formas de propiedad emergentes, lo privado y lo cooperativo. En función de cual de estos sectores se imponga el nuevo modelo económico de la isla será distinto.

En lo que respeta a otras cuestiones como la cuestión de la supremacía y aplicabilidad directa de la Constitución, organización política y participación ciudadana y la administración territorial del Estado, si bien se introducen distintas novedades, la Constitución vigente mantiene inalterado gran parte de los principios generales de la anterior, sin aportar soluciones a muchas de las deficiencias que se dan en estos ámbitos.

Title:

The Cuban Constitution of 2019: A Critical analysis

Summary:

I. INTRODUCTION. II. SOCIO-ECONOMIC TRANSFORMATIONS AND MATERIAL CONSTITUENT PROCESS IN CUBA (1991-2018): II.I. The Special Period and the Constitutional Reform Act of July 12, 1992: II.I.1. Changes in property forms. II.I.2. The regulation of foreign trade and the decriminalization of the dollar. II.II. Retreat of Fidel Castro and transformations of the last decade (2006-2017): II.II.1. Transformations in agrarian property and the reform of the Housing Act. II.II.2. Reforms in work and social security. II.II.3. The Foreign Investment Act of 2014. III. THE NEW CONSTITUTION OF 2019: ADVANCES AND DEFICIENCIES: III.I. The procedure of approval of the Constitution. III.II. The absence of supremacy and direct applicability of the Constitution. III.III. The bill of rights: lights and shadows. III.IV. The Party, the political organization and citizen participation. III.V. The territorial Administration: elimination of the Provincial Assembly and 
creation of the provincial governor. III.VI. The property and the economic model. IV. CONCLUSIONS.

\section{Resumen:}

En julio de 2018, la Asamblea Nacional del Poder Popular (ANPP) de Cuba inició el trámite de discusión de un anteproyecto de nueva Constitución cubana. Entre el 13 de agosto y el 15 de noviembre de 2018, la ANPP convocó una fase de consulta popular entre la ciudadanía destinada a la discusión y recogida de propuestas, previa al debate para su consideración en la cámara y su posterior ratificación en referéndum en febrero de 2019. La nueva Constitución cubana es la concreción jurídico-formal de un proceso constituyente material que viene refundando las relaciones económicas y sociales de la isla desde inicios de la década de los 90 hasta hoy. El presente trabajo analizará cuales han sido estas transformaciones y realizará un análisis crítico de la Constitución cubana de 2019.

\section{Abstract:}

In July 2018, the National Assembly of Cuba began the process of discussing a preliminary draft of the new Cuban Constitution. Between August 13 and November 15, 2018, the Assebly convened a phase of popular consultation among citizens for the discussion and collection of proposals, prior to the debate for consideration in the chamber and its subsequent ratification in a referendum in February 2019.

The new Cuban Constitution is the legal-formal concretion of a material constituent process that has been refounding the economic and social relations of the island since the early 90's until today. The present work will analyze what these transformations have been and will make a critical analysis of the 2019 Cuban Constitution.

\section{Palabras clave:}

Cuba; Constitución; transición; socialismo.

\section{Key words:}

Cuba; Constitution; transition; socialism. 